Review

\title{
ßII spectrin (SPTBN1): biological function and clinical potential in cancer and other diseases
}

\author{
Panyu Yang1\#, Yanyan Yang2\#, Pin Sun¹, Yu Tian¹, Fang Gao, Chen Wang4, Tingyu Zong1, Min Li³, Ying \\ Zhang ${ }^{1}$, Tao $\mathrm{Yu}^{1,3 凶}$, Zhirong Jiang ${ }^{1 凶}$ \\ 1. Department of Cardiac Ultrasound, The Affiliated Hospital of Qingdao University, Qingdao 266000, China. \\ 2. Department of Immunology, Basic Medicine School, Qingdao University, No. 308 Ningxia Road, Qingdao 266071, People's Republic of China. \\ 3. Institute for Translational Medicine, The Affiliated Hospital of Qingdao University, No. 38 Dengzhou Road, Qingdao 266021, People's Republic of China. \\ 4. Department of Physical Medicine and Rehabiliation, The Affiliated Hospital of Qingdao University, Qingdao, Shandong Province, China. \\ \#These authors are equally to this paper.
}

$\triangle$ Corresponding authors: Tao Yu, Ph.D. Department of Cardiac Ultrasound, The Affiliated hospital of Qingdao University, No. 16 Jiangsu Road, Qingdao 266000, China; Center for Regenerative Medicine, Institute for translational medicine, School of Basic Medicine, Qingdao University, 38 Deng Zhou Road, Qingdao 266021, China. Tel: +86-532-82991791; fax: +86-532-82991791; e-mail: yutao0112@qdu.edu.cn. Zhirong Jiang, M.D, Department of Cardiac Ultrasound, the Affiliated Hospital of Qingdao University, Road No. 59 Haier, Qingdao, 266100, Shandong, People's Republic of China. Tel: +86-532-82912858; fax: +86-532-82913011; e-mail: jiangzhirong2@163.com

(c) The author(s). This is an open access article distributed under the terms of the Creative Commons Attribution License (https://creativecommons.org/licenses/by/4.0/). See http://ivyspring.com/terms for full terms and conditions.

Received: 2020.08.24; Accepted: 2020.10.22; Published: 2021.01.01

\begin{abstract}
BII spectrin, the most common isoform of non-erythrocyte spectrin, is a cytoskeleton protein present in all nucleated cells. Interestingly, $\beta$ Il spectrin is essential for the development of various organs such as nerve, epithelium, inner ear, liver and heart. The functions of $\beta$ Il spectrin include not only establishing and maintaining the cell structure but also regulating a variety of cellular functions, such as cell apoptosis, cell adhesion, cell spreading and cell cycle regulation. Notably, Bll spectrin dysfunction is associated with embryonic lethality and the DNA damage response. More recently, the detection of altered $\beta$ II spectrin expression in tumors indicated that $\beta$ II spectrin might be involved in the development and progression of cancer. Its mutations and disorders could result in developmental disabilities and various diseases. The versatile roles of $\beta$ II spectrin in disease have been examined in an increasing number of studies; nonetheless, the exact mechanisms of $\beta$ Il spectrin are still poorly understood. Thus, we summarize the structural features and biological roles of $\beta$ II spectrin and discuss its molecular mechanisms and functions in development, homeostasis, regeneration and differentiation. This review highlight the potential effects of $\beta I I$ spectrin dysfunction in cancer and other diseases, outstanding questions for the future investigation of therapeutic targets. The investigation of the regulatory mechanism of $\beta / 1$ spectrin signal inactivation and recovery may bring hope for future therapy of related diseases.
\end{abstract}

Key words: $\beta$ II Spectrin; proliferation; cancers; heart; development; TGF- $\beta$

\section{Introduction}

Spectrin, first discovered in erythroid cells by Marchesi and Steersand in $1968^{1}$, is expressed in all metazoan cells and highly conserved across different species 2. Spectrin forms an extensive filamentous intracellular network that acts as a cytoplasmic scaffold for proteins ${ }^{3}$. Due to the high affinity between the $\alpha$ and $\beta$ chains, spectrin exists mainly as heterotetramers rather than autonomous $\alpha$ or $\beta$ subunits ${ }^{4}$. Spectrin is expressed in numerous tissues and cells. A protein similar to spectrin was identified in neurons and originally named fodrin 5 . Interestingly, it was later discovered that fodrin is a common spectrin in most cells 3,6 . The spectrin-based membrane skeleton is essential for the mechanical stability and elasticity of red blood cells. It mainly contributes to membrane integrity, organization and trafficking 7 . Defects in the erythrocyte membrane skeleton can lead to a variety of hemolytic anemias ${ }^{8}$. In most cells, spectrin is involved in determining cell shape and maintaining cell flexibility, intercellular 
contact, cell polarity, and proliferation ${ }^{4}$. Although spectrin has also been found in the nuclei of non-erythrocytes, its function remains to be elucidated.

In mammals, spectrin consists of modular structures of $\alpha$ and $\beta$ subunits expressed by seven genes ( $\alpha \mathrm{I}, \alpha \mathrm{II}, \beta \mathrm{I}, \beta \mathrm{II}, \beta \mathrm{III}, \beta \mathrm{IV}$, and $\beta \mathrm{V})$. The $\mathrm{\alpha I}$ and $\alpha \mathrm{II}$ spectrin isoforms are encoded by SPTA1 and SPTAN1, respectively. Conventional $\beta$ spectrin isoforms ( $\beta \mathrm{I}-\mathrm{IV})$ consist of diverse subunits that are encoded by four different genes, SPTB, SPTBN1, SPTBN2, and SPTBN4, as well as SPTBN5 encodes a large $\beta \mathrm{V}$-spectrin ${ }^{9}$.

$\beta$ II spectrin ( $\beta 2-S p e c t r i n / S P T B N 1 / \beta 2 S P / E L F$, gene SPTBN1), a dynamic intracellular protein usually located on the medial membrane of the cell. Notably, the versatile role of $\beta$ II spectrin in disease has been reported in an increasing numbers of studies, and $\beta$ II spectrin has been implicated in diseases such as cancer, neurological disorders, cardiovascular diseases, osteoporosis, and hearing loss 2,10-13. Strikingly, growing evidence associates $\beta$ II spectrin with various cancers, and expression and function vary between different tumor stages or types of $\beta$ II spectrin ${ }^{10}$. Moreover, the most serious effect was observed in mice deficient in $\beta I I$ spectrin, which caused embryonic lethality ${ }^{14}$. In recent years, $\beta$ II spectrin has been shown to be responsible for multiple diseases, highlighting the critical role of $\beta I I$ spectrin in metabolism.

In this review, we introduce the structure of $\beta I I$ spectrin and discuss the molecular mechanisms associated with its diverse protein domains, particularly the role of $\beta$ II spectrin in regulating proliferation, controlling cell adhesion and cell cycle progression, and maintaining genomic stability. Furthermore, we highlight the implications of $\beta \mathrm{II}$ spectrin deficiency or dysfunction in development and human diseases.

\section{Structural insights into $\beta$ II spectrin}

Spectrin is a complex of two similar peptides called the $\alpha$ and $\beta$ subunits 1,15 . The $\alpha$ and $\beta$ subunits are assembled side by side in an antiparallel manner to form rod-shaped $\alpha \beta$ dimers. Subsequently, the $\mathrm{N}$-terminus of each a subunit of the dimer and the C-terminus of each $\beta$ subunit interact to form a self-associated head-to-head tetramer ${ }^{4}$.

Spectrin, which has many structural motifs and is highly modular, is characterized by the presence of spectrin repeats (SRs, composed of 106 contiguous amino acid sequence motifs) ${ }^{16}$, actin-binding domains (ABDs) (calponin homology (CH) domains), EF-hands, pleckstrin homology (PH) domains, Src homology 3 (SH3) domains and many other signaling domains and motifs, and its structure contributes to the multiple functions of spectrin 17,18 .

The most common non-erythrocyte spectrin isoform is $\beta$ II spectrin, which is present in all nucleated cells and forms a large polymer complex with ankyrin and actin ${ }^{19}$. According to Broderick and his colleague, the evolutionary process from a-actinin to $\alpha \beta$-spectrin was complex. The addition of SRs extended a-actin, which led to the replication of $\alpha \beta$ ancestors and subsequent separation into $\beta$ and $\alpha$ chains. Among them, $\beta$-spectrin corresponds to the $\mathrm{N}$-terminus of the ancestor $\alpha$-actinin, and $\alpha$-spectrin corresponds to the $\mathrm{C}$-terminus. Therefore, $\beta$-spectrin is composed of the $\mathrm{CH} 1$ and $\mathrm{CH} 2$ domains followed by SRs ${ }^{20}$. Specifically, the NH2 terminal ABDs of $\beta$-Spectrin consists of a pair of $\mathrm{CH}$ domains ${ }^{21,22}$. The presence of the ABDs allows $\beta$ spectrin to interact with F-actin in a variety of different cellular situations. Connected to the ABDs of the $\beta$ subunit are 17 consecutive triple helix motifs that terminate in a carboxyl region ${ }^{23}$. Additionally, $\beta I I$ spectrin has a variety of splice variants, including "long" and "short" C-terminal regions $(\boldsymbol{\beta} \mathbf{I} \boldsymbol{\Sigma} \mathbf{1}$ and $\boldsymbol{\beta} \mathbf{I I} \boldsymbol{\Sigma} \mathbf{2}){ }^{24}$, the long $\mathrm{COOH}$ terminal region of $\beta$-spectrin has a $\mathrm{PH}$ domain 25. a-Spectrin has 22 domains: domains 1-9 and 11-21 are composed of SR, domain 10 is the $\mathrm{SH} 3$ site ${ }^{26}$, and the COOH-terminus is the EF-hand 27. The $\beta-\mathrm{H}$ spectrin contains $30 \mathrm{SR}$ sequences (Figure 1). The above depicts the structure of spectrin in mammals.

\section{Function of $\beta$ II spectrin}

\section{$\beta$ II spectrin regulates cell proliferation}

$\beta$ II spectrin has important functions in liver cell proliferation and liver regeneration. Hepatocyte proliferation was inhibited after transforming growth factor $\beta 1$ (TGF- $\beta 1$ ) stimulation 28. Insulin is a hepatocellular mitogen. Treatment of AML-12 cells (normal mouse hepatocytes) with insulin (100 nM) activates the Phosphoinositide 3-kinase (PI3K)/ Protein kinase B (Akt) pathway, which increases phosphor-Akt expression and nuclear translocation of Smad2, 3 and 4. LY294002 is an inhibitor of PI3K that can completely block Akt phosphorylation and can also significantly reduce $\beta$ II spectrin, Smad 3 and 4 in the nucleus 28 . Strikingly, this study indicated that TGF- $\beta$ /Smad pathway can be activated by $\mathrm{PI} 3 \mathrm{~K} / \mathrm{pAkt}$ signalling, which is downregulated by activating of TGF- $\beta /$ Smad pathway ${ }^{28}$. In hepatocyte proliferation, TGF- $\beta /$ Smad and PI3K/AKT signaling pathways interact to regulate proliferation, and $\beta \mathrm{II}$ spectrin is involved in these processes. Hepatocyte dedifferentiation is a crucial cellular event in the development of liver cancer ${ }^{29}$. A related study showed that $\beta$ II spectrin could promote the 
differentiation and inhibit the growth of hepatocellular carcinoma (HCC) cells in vitro ${ }^{30}$. These findings indicate that $\beta \mathrm{II}$ spectrin is vital in liver cell proliferation and promotes liver regeneration after liver resection in mice. $\beta$ II spectrin is essential for the survival of liver cells and endothelial cells. Strikingly, the loss of $\beta$ II spectrin may lead to angiogenesis stimulation ${ }^{31}$. Inadequate $\beta I I$ spectrin led to dysregulated hepatocyte proliferation as well as abnormal and uncontrolled proliferation of yolk sac vascular endothelial cells ${ }^{32}$. $\beta$ II spectrin is also necessary for embryonic liver development. $\beta$ II spectrin mutant embryos ( $\beta$ II spectrin ${ }^{-/}$) had an abnormal liver structure and enhanced hepatocyte proliferation capacity ${ }^{28}$. Moreover, another study showed that cluster of differentiation $133\left(\mathrm{CD} 133^{+}\right)$ liver stem cells (LSCs) in $\beta$ II spectrin ${ }^{+/-}$mice treated with IL6 were highly proliferative ${ }^{33}$. All of the above results indicate that the effects of the loss of $\beta \mathrm{II}$ spectrin are related to the regulation of cell proliferation.

\section{$\beta I I$ spectrin regulates differentiation and development}

Axons are important structures that connect the nervous system. They consist of parallel microtubule bundles, which act as a structural skeleton, surrounded by regularly spaced actin loops called periodic membrane skeletons. Myelin sheaths are produced by oligodendrocytes in the central nervous system (CNS) and Schwann cells in the peripheral nervous system (PNS). $\beta$ II spectrin is relatively abundant in the nervous system and has important functions ${ }^{3}$. Myelinated axons can be subdivided into some domains such as Ranvier nodes, paranodes and juxtaparanodes (Figure 2a) ${ }^{34}$. Each of these domains contains a unique protein complex consisting of glial and axon cell adhesion molecules, ion channels, and cytoskeletal/scaffold proteins. Axon complexes are anchored to the axon cytoskeleton and crucial for effective nodes formation ${ }^{35}$. The paranode contains cell adhesion molecules: neurofascin 155 on the glial membrane, Caspr and contactin ${ }^{36}$. Protein $4.1 \mathrm{~B}$ has been identified at the paranode ${ }^{37}$. In addition, the paranode also include aII/ $\beta$ II spectrin tetramers. Ranvier node's cell adhesion molecule is different from paranode. During the formation of myelin in the peripheral nervous system (PNS), Schwann cell proteins direct the aggregation of axonal cell adhesion molecules glialneurofascin 186 (NF-186) at the Ranvier node 38 . When this connection breaks, changes in both the adaptor protein $4.1 \mathrm{~B}$ and the

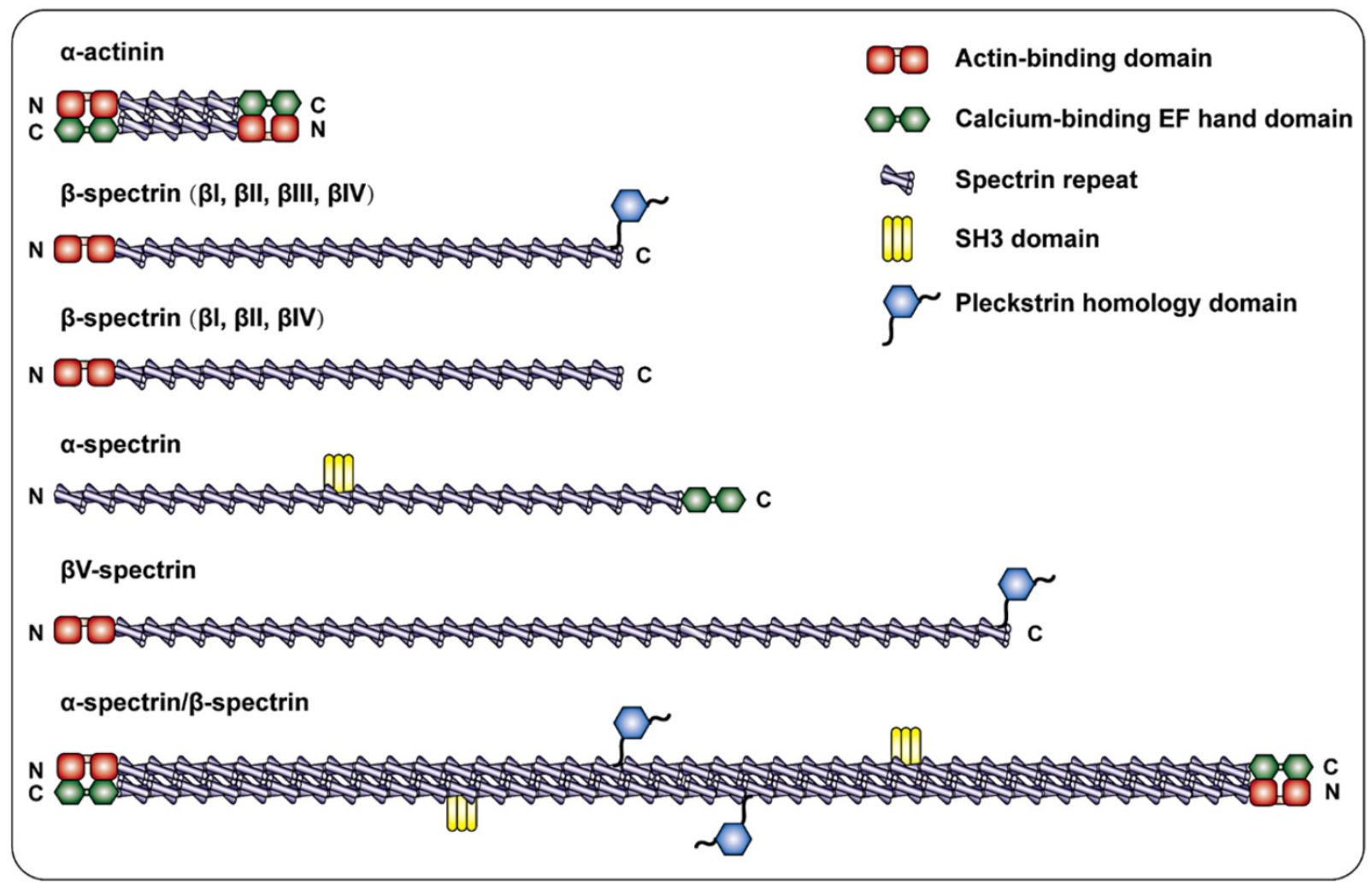

Figure 1. Schematic diagram of the spectrin family and $\alpha$-actinin. $\alpha$-actinin consists of two actin-binding domains (ABD) $\mathrm{CH} 1$ and $\mathrm{CH} 2$, four spectrin repeats, and a $\mathrm{COOH}$-terminal $\mathrm{EF}$ hand domain to form a single chain, and the two single chains are antiparallel to form dimerization body. $\beta$-spectrin is composed of two $\mathrm{CH} 1$ and $\mathrm{CH} 2$ domains at the $\mathrm{NH}_{2}$ - terminal followed by 17 spectrin repeats. $\beta \mathrm{I}, \beta \mathrm{II}$, and $\beta$ IV spectrins are cleaved into a long $\mathrm{COOH}$-terminal containing $\mathrm{PH}$ domain or a short $\mathrm{COOH}$-terminal not containing PH domain. In addition to the spectrin repeat sequence, $\alpha$-Spectrin also includes the $\mathrm{SH} 3$ site of domain 10 and the $\mathrm{EF}$ hand domain at the end of $\mathrm{COOH}$. $\beta-\mathrm{H}$ spectrin is similar in structure to other $\beta$ - spectrin, and is characterized by containing more spectrin repeats. 
cytoskeleton protein $\beta$ II spectrin in the axon lead to misalignment, and the / efficiency of Ranvier node assembly is greatly reduced ${ }^{39}$. Notably, high-density $\mathrm{Na}^{+}$channels on the nodes of Ranvier are necessary for the rapid and effective propagation of action potentials in myelinated axons ${ }^{40,41}$. A recent study showed that Ranvier nodes of $\mathrm{Na}^{+}$channels that depend on paranodes require axonal $\beta$ II spectrin, which is concentrated near the paranodes and juxtaparanodes 42, 43. Previous studies have shown that $\beta I I$ spectrin and cyclic actin loops are essential for microtubule stability 44. Silencing AnkyrinB, aII-spectrin, or $\beta$ II spectrin expression disrupted the axon initial segment (AIS) in mice and prevented AIS assembly ${ }^{45}$.

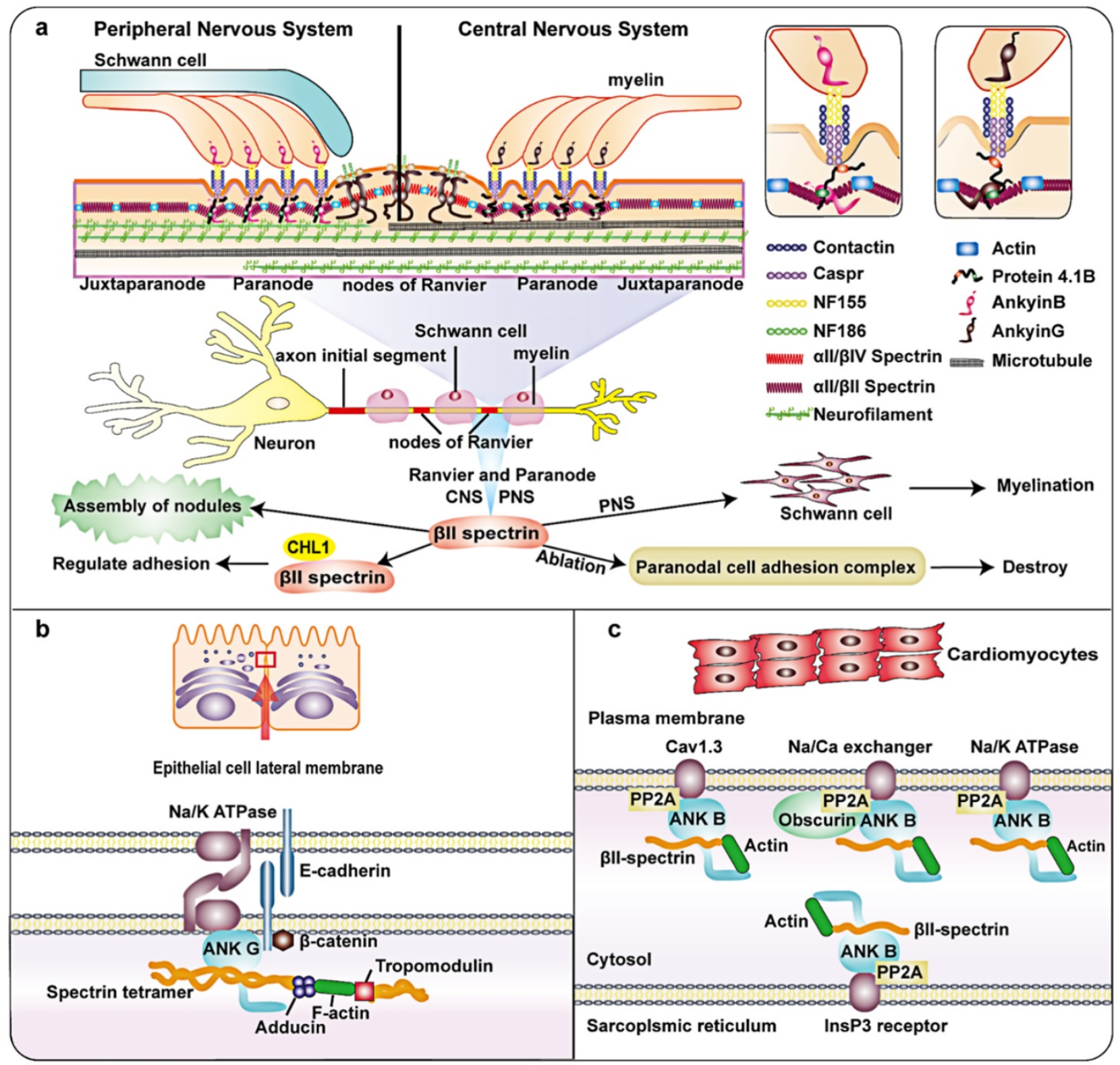

Figure 2. Schematic diagram and partial functions of $\beta$ II spectrin in nerve fibers, epithelial cells and the heart. a: Axons are composed of parallel bundles of microtubules that act as a structural skeleton. Myelin sheaths are produced by oligodendrocytes in the central nervous system (CNS) and Schwann cells in the peripheral nervous system (PNS). Myelin axons can be subdivided into Ranvier nodes, paranode and adjacent paranodes. The paranodes contain axon cell adhesion molecules (CAM), such as neurofascin 155 (NF155) on the glial membrane and a complex of Caspr and contactin on the axon. In addition, there are Protein 4.1B, all/ 3 II spectrin tetramer, and ankyrin G

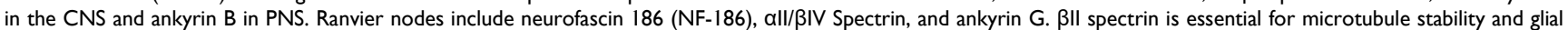
complexes. It is critical in the assembly of the axon initial segment (AIS), Ranvier and paranode. b: In the lateral epithelial membrane module, ankyrin-G, $\mathrm{E}-\mathrm{cadherin}$ and $\mathrm{Na} / \mathrm{K}+$ ATPase are combined. The F-actin bridge bound by tropomodulin is connected to $\alpha / \gamma$ adducin. $\beta$ II spectrin, adducin and ankyrin-G directly combine to form a complex. c: In the heart, $\beta$ II spectrin is involved in the localization and stability of transporters. It forms a complex with ankyrin B, which can target type $2 \mathrm{~A}$ protein phosphatase (PP2A) and plays a role in transporters such as Na/K-ATPase, Cav1.3, InsP3R and Na/Ga exchanger. In addition, Bll spectrin also binds to Actin. 
Plasma membrane-associated structural proteins promote axon stability and efficient organelle transport. A recent study in which $\beta$ II spectrin was knocked down in mouse neural progenitor cells showed that $\beta$ II spectrin is crucial to axonal transport of transmitters in the mouse brain ${ }^{46,47}$. $\beta$ II spectrin and AnkyrinB promote axonal transport through different mechanisms ${ }^{46}$. $\beta$ II spectrin without ankyrin-binding activity restores transport, and axonal transport in mice lacking $\beta I I$ spectrin and AnkyrinB was more severely compromised than that in mice lacking either protein alone ${ }^{46}$. Consistently, these results show the versatile role of $\beta$ II spectrin in axonal transport.

aII Spectrin and $\beta$ II spectrin occupy polarized positions at the axon contact site in premyelinating Schwann cells. In cultured Schwann cells, silencing of $\beta I I$ spectrin could inhibit myelination ${ }^{48}$. Observation of conditional knockout mice lacking glial $\beta$ II spetrin revealed nodes and paranodes have changed during CNS development ${ }^{49}$.

Altogether, the versatile roles of $\beta \mathrm{II}$ spectrin in regulating axon stability, axonal transport, axonal Ranvier node assembly and neurite growth have been demonstrated in increasing numbers of studies.

The sophisticated process of epithelial morphogenesis results in typical epithelial cells with unique protein distribution patterns, enabling them to perform various physiological functions ${ }^{50}$. One study indicated that reduced expression of $\beta \mathrm{II}$ spectrinand splicing recruitment play a vital role in stabilization of the connection between the pancreas and colonic epithelium and the regulation of connection remodeling ${ }^{51}$. Consistent with this, the depletion of $\beta$ II spectrin further weakened reconstruction of the cell barrier next to human intestinal epithelial cells and inhibited the formation of important structures in human bronchial epithelial (HBE) cells ${ }^{51}$. During the formation of columnar human intestinal cell apical domains, the levels of actin-binding proteins in the terminal network increased in vitro and in vivo. In addition, $\beta$ II spectrin form a complex dependent on the actin-binding protein that connects F-actin to the top of the microtubule network during epithelial cell morphogenesis ${ }^{52}$. The lateral membrane of epithelial cells is an important part of cell adhesion and salt and water homeostasis. As one of the most abundant specialized membrane domains in biology, it has important physiological significance. Studies have shown that the lateral membrane of epithelial cells may be similar to the membrane skeleton of spectrin, with spectrin and ankyrin isoforms positioned at the site of contact between cells (Figure $2 b$ ) ${ }^{53}$. Some research results have explained the possible related mechanisms. A study on the lateral membrane of epithelial cells showed that adducin adopts a new mechanism to regulate overall characteristics of the outer membrane of the bronchial epithelium by interacting with $\beta \mathrm{II}$ spectrin, which stabilizes the HBE at the lateral membranes of cells ${ }^{54}$. In addition, previous findings and recent studies have shown that $4.1 \mathrm{~N}, \quad \beta I I$ spectrin and ankyrin $\mathrm{G}$ are structural components of the lateral membrane backbone 55,56 .

The above research indicates that $\beta$ II spectrin is highly significant in the assembly of fully functional lateral membranes, the regulation of connection remodeling and stabilization of the connection with the epithelium.

Previous studies have shown that all-spectrin is involved in regulating the cytoplasmic actin network of cardiomyocytes ${ }^{57}$. In recent years, several lines of evidence have demonstrated that $\beta \mathrm{II}$ spectrin, as part of the cytoskeleton, in the heart is critical in maintaining normal development of the heart during embryogenesis. In the heart, $\beta$ II spectrin and ankyrin B form a complex. Ankyrin B can target type 2A protein phosphatase (PP2A). The complex formed by the interaction of $\beta I I$ spectrin and ankyrin-B plays an important role in the positioning and stability of ion channels and transporters (such as $\mathrm{Na} / \mathrm{K}$-ATPase, Cav1.3, InsP3R and NCX) (Figure 2c) ${ }^{58}$. Deletion of $\beta$ II spectrin during cardiac development led to cardiac developmental defects, accompanied by cardiac muscle cell differentiation and abnormal cytoskeleton formation. Consistent with this, muscle differentiation, like the expression of dystrophin, homeobox protein Nkx-2 (Nkx2.5), and alpha-smooth muscle actin (a-SMA), was markedly decreased. The mechanism involved in the destruction of $\beta$ II spectrin reduces Smad signaling in the TGF- $\beta$ signaling pathway. Studies have shown that the loss of $\beta \mathrm{II}$ spectrin can cause heart wall thickening failure and decreased cell density in the trabecular layer of the mouse heart, leading to heart developmental defects 59. These findings indicate that $\beta$ II spectrin is essential for cardiomyocyte differentiation and cardiac development.

Inner ear hair cells (HCs) is crucial in hearing and can detect sound. This process is achieved by the deflection of mechanosensory stereocilia 60 . Recent studies indicated that spectrin in HCs is essential in deafness and hearing development. In the early stages of development, HC polarity is destroyed in the loss of $\beta$ II spectrin, and the degree of destruction becomes greatest in the later stages of development, which eventually causes HCs degeneration beginning approximately 2 weeks after birth ${ }^{13}$. In addition, in different animal models of hearing loss, the spectrin loop was associated with auditory ability ${ }^{13}$. These results demonstrate the critical role of spectrin in 
auditory development in the epidermal plate.

Collectively, $\beta \mathrm{II}$ spectrin is essential for the development of organs such as nerve, epithelium, inner ear and heart. The absence of $\beta$ II spectrin causes changes in related structures, which in turn affect the function of various organ systems. Therefore, its importance in development could be considered as a potential therapeutic target in treatment of related organs in future.

\section{$\beta$ II spectrin regulates cell cycle progression}

In HCC cells, $\beta$ II spectrin can regulate the G1/S cell cycle transition through the TGF- $\beta$ signaling pathway (Figure 3). During this regulatory process, the expression of Cyclin-dependent kinase 4 (CDK4), cyclin D1 and retinoblastoma protein $(\mathrm{Rb})$ and other G1/S cell cycle checkpoint-related proteins was reduced following $\beta \mathrm{II}$ spectrin overexpression in HCC 31. $\beta$ II spectrin plays a crucial role in the translocation of Smads, and its loss caused G1/S phase transition due to the activation of cyclin D1/CDK4 in HCC ${ }^{31}$. Consistently, when $\beta$ II spectrin was removed from cardiomyocytes, mitotic activity was reduced 59 . Increasing expression of the proapoptotic protein Bax and the cleavage of caspase-7 also indicated cardiomyocyte apoptosis and dysregulation of the cell cycle ${ }^{59}$, both of which are closely related to the lack of $\beta$ II spectrin, proving that its loss causes cell cycle arrest.

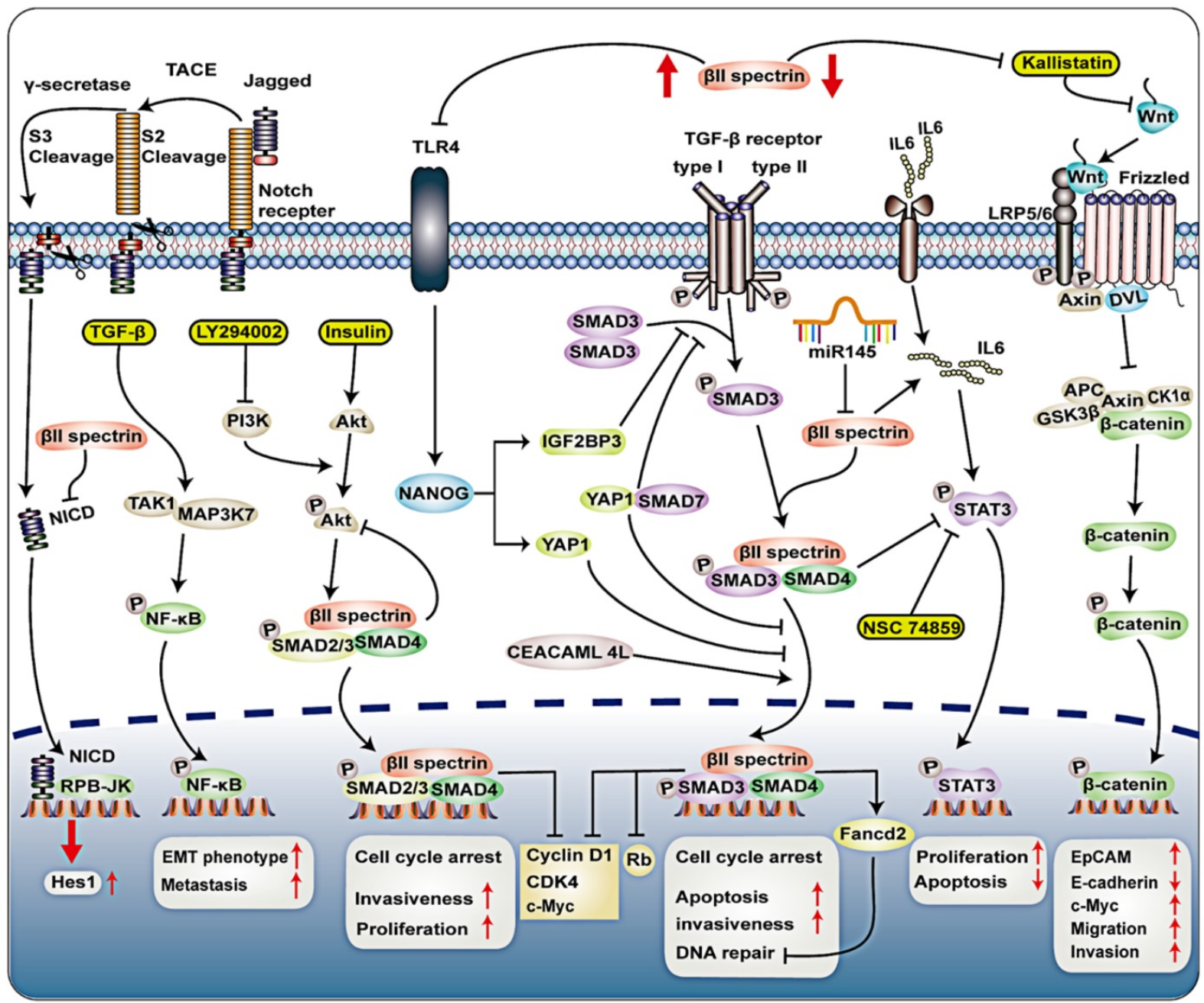

Figure 3. Signal transduction of $\beta I I$ spectrin in tumor. Loss of Smad4 and $\beta I I$ spectrin was observed in Barrett's esophagus and adenocarcinoma tissue sections. The absence of $\beta$ II spectrin/Smad4 will interrupt TGF- $\beta$ signaling, which may activate Notch signaling through the Notch signaling molecule Hes-1. In CD133+ LSCs, TAK 1-NFKB signal and TGF- $\beta$ signaling pathway activated kinase 1 (TAK1; MAP3K7), leading to increased production of metastatic CSCs. Treatment of AML-12 cells with insulin (100 nM) activates the PI3K/Akt pathway, which increases phosphor-Akt expression and nuclear translocation of Smad2, 3 and 4 . LY294002 is an inhibitor of PI3K that can completely block Akt phosphorylation and can also reduce $\beta$ II spectrin, Smad 3 and 4 in the nucleus. $\beta$ II spectrin is involved in hepatocyte proliferation through the interaction of TGF- $\beta / S m a d$ and PI3K/AKT signalling. PI3K/pAkt signalling activated TGF- $\beta /$ Smad pathway, and activation of TGF- $\beta /$ Smad pathway downregulated PI3K/pAkt signallings. CEACAMI-4L can interact with $\beta$ II spectrin, promote nuclear translocation of Smad3 in advanced HCC. TGF- $\beta$ signaling pathway upregulates Fancd 2 expression mediated by $\beta$ II spectrin and Smad3, thereby conferring genomic stability. In hepatocellular carcinoma (HCC), TLR4 activates NANOG, NANOG induces IGF2BP3 and YAP1, IGF2BP3 blocks the phosphorylation of SMAD3, YAP1 blocks the nuclear translocation of p-SMAD3. IGF2BP3-mediated activation of AKT phosphorylates YAP1, enhancing YAP1's ability to block nuclear translocation of P-SMAD3. YAPI may interact with SMAD7, and enhance the inhibitory activity and nuclear translocation of SMAD7 on TGF- $3 /$ SMAD3 signaling. By drinking alcohol, inhibiting $\beta$ II spectrin in liver cancer cells can significantly increase the expression of TLR4. IL6 can activate transcriptional activator 3 (STAT3), $\beta$ II spectrin prevented the development of $\mathrm{HCC}$ by downregulating the expression of signal transducer and STAT3. In pancreatic cancer cell lines, miR-145 induces downregulation of $\beta$ II spectrin. 


\section{$\beta$ II spectrin regulates cell adhesion and spreading}

Decreased SPTBN1 expression promoted sphere formation, tumor development and aggressive phenotypes in HCC cells ${ }^{61}$. Zhi et al. showed that epithelial cell adhesion molecule-positive (EpCAM $(+))$ cells and integral EpCAM expression were significantly increased in SPTBN1 (+/-) mice compared to wild-type mice ${ }^{61}$. Carcinoembryonic antigen-related cell adhesion molecule 1 (CEACAM1-4L) with a long cytoplasmic domain has a tumor suppressive effect and is down-regulated in HCC 62. In contrast, data from an in vitro study demonstrated that CEACAM1-4L can regulate the TGF- $\beta$ /Smad signaling pathway, interact with $\beta$ II spectrin, promote nuclear translocation of Smad3 in advanced HCC (Figure 3) ${ }^{63}$. Overexpression of CEACAM1-4L enhances the invasiveness of HCC cells. Nonetheless, clarification of the mechanism by which the overexpression of $\beta \mathrm{II}$ spectrin in liver cancer promotes the invasion of liver cancer cells needs further research.

Studies have shown that the growth of close homolog of L1 (CHL1)-dependent neurites requires regulation of the endocytosis of the $\mathrm{Ca}^{+}{ }^{+}$-dependent CHL1- $\beta$ II spectrin complex and CHL1, ligand induction, and lipid raft-dependent CHL1 adhesion regulation (Figure 1) ${ }^{64}$.

Proteomic analysis of the lack of breast cancer sensitivity gene 1 (BRCA1) in epithelial ovarian cancer (EOC) showed a 2.5-fold reduction in $\beta I I$ spectrin expression, which was related to regulation of cell migration and invasion ${ }^{65}$. As a component of the cytoskeleton, $\beta$ II spectrin has a certain regulatory effect on the cytoskeleton/actin cell adhesion in EOC. However, the expression of endometrial side population cells in patients with early and advanced disease and their underlying regulatory mechanisms require more research.

The interaction of subperitoneal fibroblasts with cancer cells in peritoneal tissues showed that validated cases with overexpression of $\beta$ II spectrin during tumor progression had a poor prognosis. Overexpression of $\beta \mathrm{II}$ spectrin may promote tumor progression and metastasis through some means (such as biological or mechanical means) 66 .

The above results indicate that the overexpression of $\beta I I$ spectrin is related to enhanced tumor aggressiveness and that its deletion is also closely related to cell adhesion and migration.

\section{$\beta$ II spectrin maintains genomic stability}

The stability of the genome is crucial to the development of diseases, especially cancer. Previous studies suggest that TGF- $\beta 1$ is a key regulator of genomic integrity ${ }^{67}$. A recent study by Chen et al. demonstrated the major role of the TGF- $\beta / S \operatorname{Smad} 3$ adapter $\beta$ II spectrin in maintaining genomic stability after alcohol-induced DNA damage (Figure 3) ${ }^{68}$. It has been suggested that the TGF- $\beta$ signaling pathway upregulates Fancd2 (a core component of the Fanconi anemia complex) expression mediated by $\beta I I$ spectrin and Smad3, thereby conferring genomic stability and proper DNA repair. $\beta$ II spectrin deficiency caused genomic instability and increased sensitivity to DNA damage. $\beta I I$ spectrin-deficient cells showed DNA crosslinking and DNA double-strand breaks after injury and stimulation ${ }^{68}$. DNA double-strand break repair defects could be repaired by ectopic Fancd 2 expression. Further studies on DNA damage repair pathways confirmed that deletion of $\beta I I$ spectrin led to a defect in homologous recombination DNA repair 68. Overall, this indicates that $\beta$ II spectrin is beneficial to DNA repair through the TGF- $\beta$ pathway.

\section{The involvement of $\beta$ II spectrin in cancer}

Notably, clinical research data shows that the expression of $\beta$ II spectrin is significantly reduced in malignant tumors such as most human HCC, lung cancer, digestive tract cancer, pancreatic cancer and so on (Fig. 4, Table 1) 30, 69-71. TGF- $\beta /$ Smad, Wnt/ $\beta$-catenin, Notch, NF-kB, IL-6/transcription 3 (STAT3) and other signaling pathways are now known to be important in the relationship between $\beta I I$ spectrin and cancer ${ }^{10}$. This raises the possibility that $\beta$ II spectrin can be used as a diagnostic biomarker and for a molecular assessment of prognosis.

Table 1. $\beta$ II spectrin changes in cancer

\begin{tabular}{|c|c|c|}
\hline Tumor Type & Changes in $\beta I I$ spectrin & References \\
\hline $\begin{array}{l}\text { Hepatocellular } \\
\text { carcinoma }\end{array}$ & $\begin{array}{l}\beta I I \text { spectrin downregulation } \\
\beta \text { II spectrin upregulation }\end{array}$ & $\begin{array}{l}32,61,62,74,75, \\
79-81 \\
81\end{array}$ \\
\hline pancreatic cancer & $\begin{array}{l}\beta I I \text { spectrin downregulation } \\
\text { miR-145 downgrade } \beta \text { II spectrin }\end{array}$ & $\begin{array}{l}73 \\
70\end{array}$ \\
\hline $\begin{array}{l}\text { Colorectal cancer } \\
\text { (CRC) }\end{array}$ & $\begin{array}{l}\text { SPTBN1-ALK fusion protein: potential targets for } \\
\text { chemotherapy }\end{array}$ & 96 \\
\hline $\begin{array}{l}\text { Esophageal } \\
\text { cancer }\end{array}$ & $\beta \mathrm{II}$ spectrin downregulation & 71 \\
\hline Lung cancer & $\begin{array}{l}\text { SPTBN1-ALK fusion: resistant to chemotherapy } \\
\text { and radiation therapy }\end{array}$ & 102 \\
\hline $\begin{array}{l}\text { Follicular } \\
\text { lymphoma }\end{array}$ & Loss of $\beta \mathrm{II}$ spectrin & 108 \\
\hline $\begin{array}{l}\text { Uveal melanoma } \\
\text { (UVM) }\end{array}$ & $\begin{array}{l}\text { Alterations in SPTBN1 is significantly associated } \\
\text { with worse prognosis }\end{array}$ & 109 \\
\hline Ovarian cancer & $\begin{array}{l}\beta I I \text { spectrin can prevent cisplatin activity and } \\
\text { enhance drug resistance }\end{array}$ & 106 \\
\hline Oropharyngeal & $\beta \mathrm{II}$ spectrin is mutated & 103 \\
\hline $\begin{array}{l}\text { squamous cell } \\
\text { carcinomas } \\
\text { (OPSCC) }\end{array}$ & $\begin{array}{l}\text { Tumor expressed spectrin were more likely to die at } \\
\text { any given time when compared with those without } \\
\text { spectrin }\end{array}$ & 104 \\
\hline $\begin{array}{l}\text { Atypical chronic } \\
\text { myeloid leukemia } \\
(\mathrm{aCML})\end{array}$ & SPTBN1-FLT3 fusion: chemotherapy target & 116 \\
\hline Gastric cancer & Loss of ELF & 101 \\
\hline
\end{tabular}




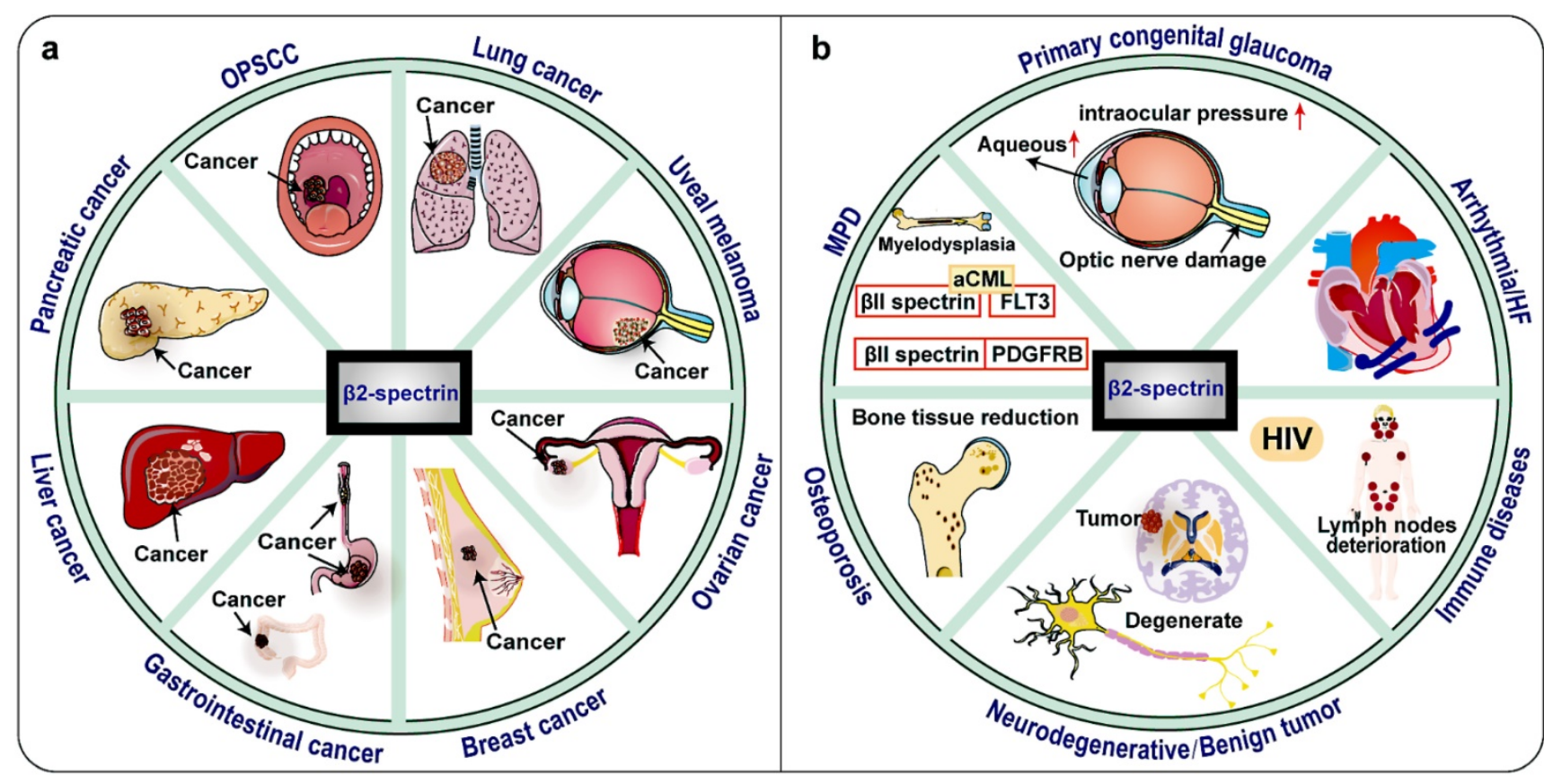

Figure 4. Tumors and other diseases related to $\beta I I$ spectrin. $\beta I I$ spectrin is associated with a variety of tumors and has a tumor suppressing effect, and its expression is down-regulated in most tumors. In some hepatocellular carcinomas (HCC), the expression of $\beta I l$ spectrin is up-regulated and the invasiveness is also increased. In HIV, $\beta$ II spectrin is related to the sensitivity of macrophages to HIV virus, and its expression is up-regulated. SPTBN1 is found to be fused with other genes in lung cancer, ovarian cancer, atypical chronic myeloid leukemia (aCML) and myeloproliferative disease (MPD). Bll spectrin is mutated in oropharyngeal squamous cell carcinomas (OPSCC), Osteoporosis and Neurodegenerative diseases. No changes in $\beta$ II spectrin expression have been found in heart failure cases.

\section{BII spectrin in liver cancer}

Most patients with HCC are already at an advanced stage when diagnosed with liver cancer, so their prognosis is poor ${ }^{72}$. Therefore, there is an urgent need to demonstrate the molecular mechanisms of liver cancer progression, as these studies are the basis for promoting the development in biomarkers and therapies for this disease.

Forty percent of $\beta \mathrm{II}$ spectrin (+/-) mice developed spontaneous HCC, and the expression of $\beta$ II spectrin was significantly reduced in most human HCC cases ${ }^{61}$. Decreased expression of $\beta I I$ spectrin is associated with shortened HCC survival 32, suggesting that this protein has the ability to inhibit tumors ${ }^{73}$. Lin et al. found that $\beta$ II spectrin prevented the development of HCC by downregulating the expression of signal transducer and transcriptional activator 3 (STAT3) ${ }^{74}$._Loss of $\beta$ II Spectrin promotes Wnt signaling activation through down-regulation of Kallistatin, increased expression of EpCAM and c-Myc, and decreased expression of E-cadherin, which are downstream genes of Wnt/ $\beta$-catenin signaling ${ }^{61}$, 75. Kallistatin is a Wnt antagonist that binds to low density lipoprotein receptor-related protein 6 (LRP6). The main component of $\beta$-catenin is strictly regulated by the destruction complex, which consists of the scaffold protein AXIN, adenomatous polyposis (APC), and the kinases glycogen synthase kinase $3 \alpha / \beta$ (GSK3) and casein kinase (CK1 1$)^{76}$. Under active conditions, Wnt ligands bind to frizzled (FZD) receptors and LRP5/6 receptors. Next, scattered scaffold proteins (DVL) and AXIN are recruited to the membrane. The chelation and degradation of AXIN leads to the disintegration of $\beta$-catenin destruction complex 77 , and then unphosphorylated $\beta$-catenin accumulates in the cytoplasm, and active $\beta$-catenin translocates to the nucleus ${ }^{78}$. Moreover, the loss of SPTBN1 and Kallistatin protein was associated with a higher recurrence rate and increased tumor migration and invasion (Figure 3) ${ }^{61}$. Previous studies have demonstrated that toll-like receptor 4 (TLR4) and TGF- $\beta$ pathways have antagonistic effects in HCC ${ }^{79}$. Knocking down $\beta 2-S p e c t r i n$ in liver cancer cells can significantly increase the expression of TLR4 and enhance the self-renewal and tumorigenic activity of the cells. TLR4 activates NANOG, NANOG induces IGF2BP3 and Yes-associated protein 1 (YAP1), IGF2BP3 blocks the phosphorylation of SMAD3, YAP1 blocks the nuclear translocation of p-SMAD3, thereby blocking the TGF- $\beta$ pathway ${ }^{79}$, IGF2BP3 and YAP1 are Tumor-initiating stem-like cells (TICs) oncogene ${ }^{80}$. In addition, IGF2BP3-mediated activation of AKT phosphorylates YAP1, thereby enhancing YAP1's ability to block nuclear translocation of p-SMAD3 ${ }^{79}$. YAP1 may interact with SMAD7, and enhance the inhibitory activity and nuclear translocation of SMAD7 on TGF- $\beta /$ SMAD3 signaling ${ }^{62}$. By drinking alcohol, inhibiting $\beta$ II-Spectrin in liver cancer cells can significantly 
increase the expression of TLR4, and enhance the self-renewal and tumorigenic activity of cells (Figure 3) ${ }^{79}$. Altogether, these data suggest that $\beta$ II spectrin plays a tumor-suppressive role that is executed through diverse signaling pathways in HCC.

Nonetheless, one study demonstrated that $\beta I I$ spectrin was overexpressed in a highly metastatic HCC cell line, was highly expressed at the fragment level in human HCC cell lines ${ }^{81}$. The mechanism by which overexpression of $\beta$ II spectrin in liver cancer accelerated the invasion of liver cancer cells needs further research. Biomarker-driven targeted therapies for HCC in the future may also include DNA repair pathways and, along with other signal transduction pathways, may alter the course of this deadly cancer.

\section{$\beta$ II spectrin in pancreatic cancer}

The treatment of most pancreatic cancer patients with chemotherapy is difficult because these patients are usually diagnosed with metastatic advanced pancreatic cancer. Therefore, the need to better understand the molecular mechanisms of pancreatic tumorigenesis and test new chemopreventive and chemotherapeutic compounds to establish practical methods for early detection remains.

Low expression of the $\beta$ II spectrin protein indicates a worse prognosis, and decreased expression of $\beta$ II spectrin was related to a shorter survival time in patients with pancreatic cancer, suggesting that the protein has a tumor-suppressive function, as shown in other malignant tumors of the gastrointestinal tract 73,82 . In recent years, the role of non-coding RNA in disease has been extensively studied ${ }^{83-92}$. Pancreatic cancer cell line-based miRNA analysis and quantitative proteomics analysis revealed that miR-145 induced the downregulation of some protein linked to cancer, including $\beta I I$ spectrin (Figure 3) ${ }^{70}$. This study revealed previously unreported miR-145 targets and provided new insights into the tumor-suppressive mechanisms of $\beta$ II spectrin. $\beta$ II spectrin(+/-) mice serve as an important animal model for lethal gastrointestinal and pancreatic cancers ${ }^{93}$. In short, $\beta$ II spectrin is closely related to the development and prognosis of pancreatic cancer, but its specific regulatory mechanism in pancreatic cancer needs further research.

\section{$\beta I I$ spectrin in colorectal cancer, esophageal cancer and gastric cancer}

Colorectal inflammation may be the basis of tumor occurrence and progression ${ }^{94,95}$. In automated immunohistochemistry assay-positive colorectal cancer (CRC) cases, target gene enrichment and sequencing showed that Anaplastic lymphoma kinase (ALK) was fused with a new partner, SPTBN1. The authors concluded that this new SPTBN1-ALK fusion gene and other ALK fusion genes could be potential targets for anti-ALK therapy ${ }^{96,97}$. Therefore, SPTBN1 has an important regulatory role in CRC that is mainly related to its antitumor effect.

The loss of Smad 4 and $\beta 2$ spectrin was observed in Barrett's esophagus and adenocarcinoma tissue sections ${ }^{71}$. This study indicates for the first time that $\beta$ II spectrin is important in the loss of TGF- $\beta$ signaling pathway and activation of Notch signaling pathway in esophageal adenocarcinoma. The absence of $\beta \mathrm{II}$ spectrin/Smad4 will interrupt TGF- $\beta$ signaling, which may activate Notch signaling through the Notch signaling molecule Hes-1 (Figure 3). The TGF- $\beta$ pathway is necessary for stem cell differentiation, but Notch maintains the undifferentiated phenotype of stem cells ${ }^{98}$. The interaction between TGF- $\beta$ and Notch pathway is crucial for the transformation of esophageal stem cells. Therefore, restoring abnormal TGF- $\beta$ signaling function or inhibiting Notch signaling may become a new treatment for esophageal adenocarcinoma.

$\beta$ II spectrin is critical in the development of gastric cancer through the TGF- $\beta$ signaling pathway, inhibiting tumors and regulating gastrointestinal epithelial cell adhesion 99,100 . Study on gastric cancer demonstrates that $\beta$ II spectrin $/ /-/$ smad $^{+/-}$mice are important model of gastric cancer ${ }^{101}$. $\beta$ II spectrin can inhibit the occurrence of gastric cancer. $\beta$ II spectrin loss-mediated disruption of TGF- $\beta$ signaling, which leads to abnormal cell cycle regulation and promotes faster entry into the $S$ phase ${ }^{101 .}$

\section{$\beta I I$ spectrin in lung cancer}

In some lung cancer cell lines, $\beta$ II spectrin expression is insufficient, and CDK4 expression increases ${ }^{69}$. It shows that the role of $\beta$ II spectrin in lung cancer is similar to other tumors. One report described a rare case of advanced lung adenocarcinoma with SPTBN1-ALK fusion resistant to chemotherapy and radiation therapy in a 69-year-old non-smoking Chinese male ${ }^{102}$. Notably, the prognosis was relatively poor ${ }^{102}$. The SPTBN1-ALK fusion gene may be a biomarker for refractory cancer and a target for antitumor therapy.

\section{$\beta I I$ spectrin in head and neck disease}

The genetic characteristics of oropharyngeal squamous cell carcinoma (OPSCC) associated with human papillomavirus-positive are currently unknown. The mutation of SPTBN1 is closely related to the occurrence of OPSCC 103, but the specific molecular mechanism of this change is not clear. Another HPV-negative study of OPSCC demonstrated that spectrins are significantly related 
to poor prognosis 104. Collectively, these studies increase the possibility that SPTBN1 is a useful biomarker in OPSCC, but further research is required to clarify this suggestion.

\section{$\beta I I$ spectrin in ovarian cancer and breast cancer}

In the context of ovarian cancer metastasis and cell migration, little is known about the role of $\beta \mathrm{II}$ spectrin. A recent study indicated that $\beta$ II spectrin mediates the inhibition of JAK/STAT signaling pathway through suppressor of cytokine signaling 3 (SOCS3), thereby inhibiting cell growth and migration in epithelial ovarian cancer 105. Additionally, $\beta \mathrm{II}$ spectrin has been shown to be involved in the resistance of serous ovarian cancer to cisplatin treatment ${ }^{106}$. The research on drug resistance in ovarian cancer showed that the Spectrin aII and $\beta \mathrm{II}$ of cytoskeleton proteins can prevent cisplatin activity and enhance drug resistance 106. Due to the development of drug resistance in ovarian cancer, the molecular mechanism of drug resistance must be elucidated, which is conducive to the best choice of clinical treatment, and the sensitivity of anticancer drugs affects the prognosis of ovarian cancer.

$\mathrm{SH} 3$ domain-binding glutamic acid-rich-like protein 2 (SH3BGRL2) has a dual role in breast tumors. The latest research found that SH3BGRL2 inhibits the proliferation of breast cancer cell lines in vitro and the growth of xenograft tumors in vivo ${ }^{107}$. Further research found that SH3BGRL2 promotes breast cancer cell migration and invasion by inhibiting the expression of SPTAN1 and SPTBN1. Current research has confirmed that SPTBN1 has changed in breast cancer, but the specific mechanism and role of SPTBN1 in breast cancer need to be further clarified.

\section{BII spectrin in Lymphoma}

The expression of spectrin isoforms in B-cell malignant lymphomas remains unknown. To the best of our knowledge, there has been no comprehensive analysis of spectrin expression in lymphoid malignancies. Spectrin appeared to be downregulated in some cases of classical Hodgkin's lymphoma and nodular lymphocyte-dominant Hodgkin's lymphoma compared to lymphocytes in reactive lymphoplasia 108. Changes in spectrin gene expression in lymphomas may also be related to other gene-silencing mechanisms, such as hypermethylation of DNA, point mutations, and transcriptional repression. There has been little research on the expression of $\beta I I$ spectrin in lymphoma, but they are certainly related. The causal relationship between the specific pattern of spectrin loss and expression in B-cell malignant lymphoma must be confirmed by additional mechanistic studies.

\section{$\beta I I$ spectrin in uveal melanoma (UVM)}

Uveal melanoma (UVM) is the most common adult intraocular malignant tumor with a high metastatic tendency. $\beta$ II spectrin is an independent prognostic factor for UVM, and its transcription level has high prognostic value and thus may help us better identify UVM or assess UVM progression ${ }^{109}$. Therefore, SPTBN1 is an important biomarker for diagnosis.

\section{The involvement of $\beta I I$ spectrin in other disease}

In addition to $\beta$ II spectrin has an important regulatory role in a variety of cancers, $\beta$ II spectrin participates in many organ system diseases, such as immune system diseases, nervous system diseases, and circulatory system diseases and so on (Figure 4, Table 2).

Table 2. $\beta$ II spectrin in other diseases

\begin{tabular}{|c|c|c|}
\hline Disease Type & Changes in $\beta \mathrm{II}$ spectrin & References \\
\hline Arrhythmia & $\beta \mathrm{II}$ spectrin downregulation & 17,112 \\
\hline Heart failure (HF) & No change & 113 \\
\hline $\begin{array}{l}\text { Myeloproliferative } \\
\text { disease (MPD) }\end{array}$ & $\begin{array}{l}\text { SPTBN1-PDGFRB: chemotherapy } \\
\text { target }\end{array}$ & 117 \\
\hline Osteoporosis & Variation in SPTBN1 expression & $12,118-121,123-128,14 \div$ \\
\hline $\begin{array}{l}\text { Neurodegenerative } \\
\text { diseases }\end{array}$ & $\beta \mathrm{II}$ spectrin mutation & 137 \\
\hline HIV & $\beta \mathrm{II}$ spectrin upregulation & 140 \\
\hline $\begin{array}{l}\text { Primary congenital } \\
\text { glaucoma (GLC3) }\end{array}$ & Related candidate gene & 143 \\
\hline $\begin{array}{l}\text { Beckwith-Wiedemann } \\
\text { syndrome (BWS) }\end{array}$ & Loss of $\beta I I$ spectrin & 93 \\
\hline
\end{tabular}

\section{BII spectrin in heart diseases}

In the heart, the cytoskeleton is crucial in maintaining the structural integrity of myocardial cells. Likewise, $\beta I I$ spectrin is also critical in maintaining normal development of the heart during embryogenesis ${ }^{59}$. The development of severe heart disease, such as congenital arrhythmia, heart failure $(\mathrm{HF})$, and congenital heart disease, is closely related to mutations in the $\beta$ II spectrin gene.

\section{Effects of $\beta$ II spectrin on myocardial excitability}

As mentioned above, the integrity of the cytoskeleton associated with cardiomyocytes is an important component to maintain the normal function of cardiomyocytes 110. Membrane-bound ionophore proteins such as channels and transporters have normal coordinated activity and are critical for the normal beating of the heart and the excitability of the heart. Mutations in the proteins that make up the transport device, cytoskeleton proteins and related proteins can cause arrhythmias. Studies have shown 
that $\beta \mathrm{II}$ spectrin is localized in the intracellular compartment of mouse neonatal cardiomyocytes, $\beta$ II spectrin and ankyrin B are colocalized in the stripe above the $\mathrm{M}$ line ${ }^{111}$. The myocardial ankyrin-B- $\beta \mathrm{II}$ spectrin complex is closely related to the inner cell membrane. Elucidating the location, composition, and function of $\beta I I$ spectrin and ankyrin B in myocardial cells and their relationship with cell membrane growth will be important targets for future research. The actin-related molecule $\beta$ II spectrin is critical for posttranslational targeting and the localization of key membrane proteins in the heart. Mice lacking cardiotype $\beta$ II spectrin exhibited fatal arrhythmias, abnormal electrical and calcium handling phenotypes, and abnormal expression/localization of cardiac membrane proteins 17,112 . The ankyrin-B/ $\beta$ II spectrin interaction is the basis of key ionophore protein localization and key excitation-contraction coupling protein expression levels. In summary, these findings provide a new mechanism for human excitatory cell disease and reveal a new role for the cardiac cytoskeleton in human cardiovascular disease.

\section{Effects of $\beta$ II spectrin on heart failure ( HF ) and remodeling}

A previous study compared changes in gene expression in the heart muscle of patients with worsening HF and stable end-stage failure after left ventricular assist device (LVAD) implantation. There was no obvious change in the expression level of the cytoskeleton protein marker $\beta I I$ spectrin among donors at the end of disease in the stable HF group or in the group with worsening HF ${ }^{113}$. $\beta$ II spectrin levels are known to be significantly changed in human cardiovascular disease and animal cardiovascular disease models, and molecular mechanisms related to $\beta$ II spectrin are emerging targets in the study of HF 114. The critical role of $\beta I I$ spectrin in LVAD remodeling showed that the mechanism of transcriptional mouse cardiac ankyrin repeat protein regulation was altered due to the lack of $\beta$ II spectrin expression in cardiac cells 115 .

These findings indicate that $\beta$ II spectrin is essential for the normal electrical activity of cardiac muscle cells and cardiac remodeling. Studying the link between this molecule and human heart disease has provided new insights into the biological mechanisms of cardiac muscle cells.

\section{$\beta I I$ spectrin in myeloproliferative disease (MPD)}

MPD is a group of tumorous diseases caused by the continuous clonal proliferation of one or more differentiated mature bone marrow cell lines. A clinical case analysis found that SPTBN1-type III receptor tyrosine kinase (FLT3) fusion was rare in atypical chronic myeloid leukemia (aCML), but abnormal FLT3 was sensitive to immunotherapy, and as a new type of constitutively active tyrosine kinase, it was also sensitive to tyrosine kinase inhibitor therapy ${ }^{116}$. Previous studies have reported that the platelet-derived growth factor receptor $\beta$ (PDGFRB) gene had undergone chromosomal translocation in some patients with atypical MPD. Another clinical case analysis of MPD revealed that the PDGFRB gene encodes a tyrosine kinase receptor. SPTBN1, its newly identified genetic partner, could fuse with PDGFRB to cause its constitutive activation 117 . Furthermore, the patient achieved complete molecular remission after treatment with imatinib mesylate ${ }^{117}$. This indicates that targeting of the product of the fusion of these genes provides important insight and has research significance for underlying disease pathogenesis, diagnosis, treatment and prognosis. Therefore, fusion and rearrangement of SPTBN1 with other genes are critical to the chemotherapy chosen and clinical prognosis.

\section{BII spectrin in osteoporosis}

Although several genome-wide association studies (GWAS) have confirmed the close association between $\beta$ II spectrin and osteoporosis 12, 118-122, the mechanism of its role in bone pathophysiology is unknown. Osteoporosis is a disease characterized by low bone mass and microstructural degradation of the bone tissue, resulting in an increased risk of fracture. This increases the possibility that the $\beta I I$ spectrin gene has great importance in regulating bone mass in women. Studies have shown that $\beta$ II spectrin, a gene associated with osteoporosis, may participate in the pathology of osteoporosis ${ }^{123}$. Recently, $\beta$ II spectrin gene were related to serum periostin levels and genetic variations in bone microstructure ${ }^{124}$. As a result, osteoporosis is highly hereditary. Consistent with this finding, several evidence indicate that some single-nucleotide polymorphisms (SNPs) in $\beta \mathrm{II}$ spectrin are associated with osteoporotic fractures 12 , 125. These variations indicate osteoporosis susceptibility genes in Han and European populations 126. Bone mineral density (BMD) is a highly genetic indicator of osteoporotic fracture and the most widely used indicator of fracture risk. A genome-wide meta-analysis revealed that $\beta$ II spectrin were associated with fracture risk 12,127 . These findings reveal the genetic structure and pathophysiology of changes in bone density and fracture susceptibility. In a GWAS of BMD, TGF signal transduction molecules ( $\beta$ II spectrin) were shown to be involved in key biological pathways involving bone and 2p21 ( $\beta I I$ spectrin) loci associated with fracture risk 128. 
Consequently, these findings may provide new insights into underlying genetic assays and jointly identified mechanisms of osteoporosis.

\section{$\beta$ II spectrin in nervous system diseases}

Previous studies have shown that actin, spectrin, and related molecules form membrane-associated periodic skeletons (MPSs) in axons 129, 130. Trophic deprivation (TD) causes rapid breakdown of MPS 131 . $\beta$ II spectrin may play a role in MPS formation and is a new factor in TD-induced retrograde signals and axonal mutations.

$\beta$ II spectrin has been identified as one of the components of neocortical Lewy bodies 132 . a-Synuclein (a cytosolic neuronal protein) has multiple functions as the main component of Lewy bodies and Lewy neurites. In Parkinson's disease, pathological markers to judge the survival of neuronal cells can be found in Lewy bodies and Lewy neurites. $\beta$ II spectrin is critical in the normal physiological function of axons. The results of a related study suggest that a-synuclein regulates neurite growth by interacting with cytoskeletal proteins such as $\beta$ II spectrin ${ }^{133}$. Another study found that presynaptic $\beta$ II spectrin/ $\alpha$-spectrin heterodimers play a vital physiological role in stabilizing synapses and are also involved in regulating the exocytosis of neurotransmitters ${ }^{134-136}$. Similarly, in dopaminergic neurons, $\beta$ II spectrin was essential in regulating growth and could participate in the regulation of neurite growth as well as a-synuclein ${ }^{133}$. Lewy body dementia is a disease associated with a-synuclein characterized by neocortical Lewis-associated pathology (LRP). Studies have shown that $\beta$ II spectrin may be associated with LRP ${ }^{137}$. Therefore, $\beta$ II spectrin may be critical for neurodegenerative diseases.

Neurofibromatosis 2 (NF2) protein (merlin; schwannomin) is involved in the tumorigenesis of some schwannomas and meningiomas, and has an inhibitory effect on the tumor ${ }^{138}$. In benign tumors of the human nervous system, mutations in NF2 are common. Many meningiomas and ependymomas do not have NF2 protein, especially almost all schwannomas ${ }^{139}$. Changes in the cytoskeleton are early events in the pathogenesis of certain tumor types. Under normal conditions, the interaction between the NF2 and $\beta$ II spectrin actin binding sites occurs. When NF2 is mutated, the binding is reduced, which changes the normal shape of the cell membrane skeleton and leads to the occurrence of tumors ${ }^{139}$.

Collectively, the versatile roles of $\beta I I$ spectrin in regulating axon stability, axonal transport, axonal Ranvier node assembly, neurite growth, neurodegenerative diseases and benign tumors of the nervous system have been demonstrated in increasing numbers of studies.

\section{BII spectrin in immune system diseases}

Macrophages are significant in HIV-1 infection and serve as the main target of HIV-1. The knockdown of $\beta$ II spectrin severely damaged the cytoskeleton structure, so $\beta$ II spectrin is necessary to maintain the macrophage actin cytoskeleton structure. Interleukin 27 (IL-27) is a pleiotropic cytokine that is crucial and has many functions in the immune system 140. Studies have shown that monocytes differentiate into macrophages after their activation by IL-27 and that macrophages are not sensitive to HIV-1 infection. In monocytes, $\beta$ II spectrin expression was not detected, but it was found to be significantly upregulated during macrophage differentiation, and IL-27 caused a decrease in the sensitivity of macrophages to HIV-1 infection by inhibiting $\beta$ II spectrin expression. In contrast, overexpression of $\beta$ II spectrin increases sensitivity. Specifically, IL-27 downregulated $\beta \mathrm{II}$ spectrin expression through TAK-1-mediated mitogen-activated protein kinase (MAPK) signaling pathways. $\beta$ II spectrin can act as an intracellular adaptor of HIV-1 viral particles after they enter macrophages. The results of this study have demonstrated that $\beta I I$ spectrin is an essential host factor for macrophage HIV-1 infection. Of course, the exact role of $\beta$ II spectrin on macrophages throughout the life cycle of HIV-1 infection needs further study.

\section{BII spectrin in eye diseases}

Intraocular pressure (IOP) is one of the major risk factors for glaucoma. The study of genetic factors closely related to IOP can simultaneously provide new insights into the genetic mechanism of glaucoma and new directions and methods for the clinical diagnosis and treatment of glaucoma. A GWAS showed that $\beta \mathrm{II}$ spectrin expression is an eye-related phenotype ${ }^{141}$ that is also closely related to IOP ${ }^{142}$. The relationship between $\beta$ II spectrin and IOP revealed in this study not only increased our understanding of biomarkers in IOP but also provided important insights into the genetic markers of glaucoma and will provide future genetic screening and treatment methods for glaucoma related to IOP. Furthermore, new molecular markers may be identified. Primary congenital glaucoma (GLC3) is a hereditary eye disorder that may be associated with $\beta$ II spectrin ${ }^{143}$. Studies have suggested that $\beta$ II spectrin can be used as a biomarker with diagnostic value in some eye diseases. Likewise, it also has significant prognostic value.

\section{BII spectrin in stem cell disease}

Cancer stem cells (CSCs) in HCC have functions that trigger tumorigenesis, metastasis and drug 
resistance. The main reason for the induction of HCC is the alteration of key pathways that inhibit tumorigenesis in its stem cells. However, the molecular mechanism by which metastatic stem cells are produced is unclear. The authors speculate that the main reason for the transformation of genetically defective LSCs into highly metastatic liver cancer cells in precancerous liver tissue is chronic inflammation ${ }^{33}$. This was demonstrated in a model of chronic inflammation in $\beta I I$ spectrin-expressing $(\beta I I$ spectrin $^{+/-}$) mice, where were highly tumorigenic and metastatic and positive for Epithelial-mesenchymaltransition (EMT) ${ }^{33}$. In CD133 ${ }^{+}$LSCs, this process involves constitutive activation of the transforming growth factor- $\beta$-activated kinase 1 (TAK1)- Nuclear factor kappa -light-chain-enhancer of activated B cells (NFkB) signal by an inflammatory program mediated by IL6 ${ }^{33}$. Another study demonstrated that IL6 can activate STAT3, thereby inducing the HCC process (Figure 3) ${ }^{144}$. The TGF- $\beta$ signaling pathway is also involved in the above process, activated kinase 1 (TAK1; MAP3K7 mitogen-activated protein kinase kinase kinase 7 (MAP3K7)), leading to increased production of metastatic CSCs ${ }^{33}$. This study showed for the first time that $\beta$ II spectrin inhibits the development of metastatic clones and CSCs through the TGF- $\beta$ pathway. In short, the molecular interaction between $\beta$ II spectrin and IL6 as a mechanism for the development of CSCs provides new directions and insights. Another event in the development of liver cancer that cannot be ignored is the dedifferentiation of liver cells. Related studies have shown that $\beta$ II spectrin plays a role in promoting differentiation and inhibiting growth in vitro during the differentiation of LSCs ${ }^{68}$. In addition, $\beta$ II spectrin can inhibit the transcriptional activity of liver CSC markers through $\beta$-catenin. In conclusion, $\beta$ II spectrin plays a role in promoting the differentiation of liver CSCs, leading to the inhibition of CSC function in liver cancer-initiating cells. Restoration of $\beta$ II spectrin expression may become a new method to prevent and treat liver cancer.

Beckwith-Wiedemann syndrome (BWS) is an overgrowth of stem cells ${ }^{145}$, and one of its causes is the loss of $\beta$ II spectrin ${ }^{93}$. Epigenetic silencing of the SMAD3/4 scaffold protein $\beta$ II spectrin may be the causative factor of BWS ${ }^{146}$. Two heterozygous $\beta I I$ spectrin $^{+/-/ S m a d 3} 3^{+/-}$mice developed a variety of tumors due to defective TGF- $\beta$ signaling, and the phenotypes of these tumors were highly similar to those in BWS patients ${ }^{146}$. Nonetheless, the specific molecular mechanism of $\beta$ II spectrin in the disease and whether the recovery of $\beta I I$ spectrin has a therapeutic effect on BWS need more explicit research. In conclusion, $\beta$ II spectrin has important potential for molecular therapy in the future.

\section{The potential of $\beta$ II spectrin (SPTBN1) as a therapeutic target}

$\beta$ II spectrin is a widely expressed protein with multiple functions. Its mutations and disorders affect the normal growth and development of organs ${ }^{59}$. $\beta$ II spectrin contains many phosphorylation sites and can be used as a potential modulator of the interaction between proteins. Thr-2159 specifically exists in $\beta I I \Sigma 2$-spectrin, and its phosphorylation reduces the affinity of the C-terminal region of $\beta I I \Sigma 2$ and the N-terminal region of aII subtype. In in vitro experiments, although the affinity of mutant T2159E with aII-spectrin is reduced, it does not prevent the remodeling of cell shape and the growth of neurites ${ }^{24}$. Interestingly, during the growth of neurites, $\beta I I \Sigma 2$-spectrin with mutation T2159A can effectively inhibit growth ${ }^{24}$. Therefore, T2159 site can be used as a potential therapeutic target in related organ development. Moreover, $\beta \mathrm{II}$ spectrin was also demonstrated to be essential for heart development. In SPTBN1 gene conditional knockout mice, the embryonic heart development was affected and the heart structure had obvious defects ${ }^{59}$. Especially after E14.5, the ventricular wall of the mutant embryo heart cannot be thickened ${ }^{59}$. Collectively, all these evidence indicated that mutations and deletions of $\beta$ II spectrin cause developmental abnormalities and thus affect organ functions. And the expression level of $\beta I I$ spectrin has important diagnostic significance in congenital dysplasia, and $\beta$ II spectrin may be a therapeutic target for reversing developmental abnormalities. Additionally, $\beta$ II spectrin $\%$ - mice and $\operatorname{smad} 2^{+/-} / \operatorname{smad} 3+/-$ mutant mice showed similar phenotypes 14, 147. The mice died in the second trimester of pregnancy because of developmental defects in the gastrointestinal tract, liver, heart and nerves ${ }^{14}$. Notably, many phenotypic characteristics of $\beta$ II spectrin $\%$ mice are similar to those of BWS patients, such as visceral hypertrophy, megaglossia, abnormal ear folds, etc 93, 146. Therefore, the $\beta I I$ spectrin mutation may be involved in the mechanism of human BWS. It also includes several malignant tumors that occur within a few months, such as liver cancer, stomach cancer, bowel cancer, pancreatic cancer, kidney cancer, and adrenal adenocarcinoma ${ }^{32,}$ 93, 148. Moreover, abnormal angiogenesis exists in HCC from $\beta$ II spectrin $\%$ mice, indicating its role as an angiogenesis regulator that inhibits HCC ${ }^{31}$. In short, the in-depth study targeting $\beta$ II spectrin is of great value for early detection of these diseases, formulating new treatment strategies and determining biomarkers of related diseases. 
To date, the changes of $\beta \mathrm{II}$ spectrin in clinical diseases cannot be ignored. As mentioned above, previous studies have also demonstrated that SPTBN1 was down-regulated in a variety of cancers, such as hepatocellular carcinoma, gastrointestinal tumors and lung cancer 10,30,69. At the same time, its expression level is closely related to the patient's prognosis, such as hepatocellular carcinoma, pancreatic cancer and lung cancer $61,66,72,73,102$. This increases the possibility of SPTBN1 as a biomarker for cancer diagnosis and prognosis. As well known, the choice of cisplatin could significantly improve the prognosis of patients with ovarian cancer. In the study of clinical cases, it was found that aII spectrin and $\beta I I$ spectrin can prevent the activity of cisplatin to promote drug resistance ${ }^{106}$. For cases where drug resistance may occur, if the treatment drugs for refractory cases can be determined in advance, then the side effects of patients can be greatly reduced, the treatment effect and prognosis of patients can be improved. Therefore, drugs that target the $\beta$ II spectrin resistance mechanism will improve the effectiveness of chemotherapy in refractory cases. Moreover, the SPTBN1-ALK fusion gene found in lung adenocarcinoma may become a potential biomarker for refractory cancer, and the prognosis is relatively poor 102. Therefore, in the selection of treatment methods, the new SPTBN1-ALK fusion gene may be a potential target for anti-cancer therapy.

In conclusion, $\beta \mathrm{II}$ spectrin is critically involved in the development and occurrence of diseases, especially neurodevelopment and cancer progression. Future research on $\beta$ II spectrin as a diagnostic and therapeutic target will provide new options for the treatment of a variety of human diseases.

\section{Conclusion and outlook}

As mentioned above, $\beta$ II spectrin is indispensable for normal growth and development of organs. Deletion of $\beta$ II spectrin resulted in changes in various cellular functions, such as proliferation, differentiation, apoptosis, the cell cycle and adhesion. Additionally, $\beta$ II spectrin is associated with DNA damage repair and EMT. In this review, we have summarized data showing that $\beta \mathrm{II}$ spectrin dysfunction or deficiency can lead to arrhythmia, HF, neurodegeneration, osteoporosis and embryonic death. We also reviewed what is currently known about the role of $\beta$ II spectrin in CSCs and immune disease. Notably, $\beta$ II spectrin is involved in the infection of human macrophages with HIV-1. This is an exciting discovery and provides new insights into the treatment of HIV. Nonetheless, the signaling pathways and molecular mechanisms involved in the occurrence and development of the above diseases need to be further studied.

Strikingly, a recently published study described that $\beta$ II spectrin is critical for CRC through TGF- $\beta$ signaling. It suggested that $\beta$ II spectrin has great potential in exploring the genesis and development of $\mathrm{CRC}$ and as a therapeutic agent. In addition to the vital role of $\beta$ II spectrin in CRC, low $\beta I I$ spectrin expression in patients with pancreatic cancer indicates a poor prognosis and shorter survival time. Notably, $\beta$ II spectrin plays a dual role in liver cancer. Several related pieces of evidence have demonstrated that the expression of $\beta \mathrm{II}$ spectrin is significantly reduced in most human HCC cases. Nevertheless, $\beta$ II spectrin was overexpressed in a highly metastatic HCC cell line. Interestingly, overexpression of $\beta$ II spectrin in liver cancer accelerated the invasion of liver cancer cells, but the mechanism of this process requires further research. $\beta$ II spectrin has been shown to be involved in the resistance of serous ovarian cancer to cisplatin treatment, and the fusion of SPTBN1 with other genes also causes resistance. Due to the development of drug resistance, its molecular mechanism must be elucidated, which will be conducive to selecting the best clinical treatment. These results suggest that targeting of the fusion product of these genes has important insight and research significance into underlying disease pathogenesis, diagnosis, treatment and prognosis.

Altogether, there is growing evidence that $\beta \mathrm{II}$ spectrin has not only predictive but also prognostic value. Therefore, an in-depth understanding of the biology of $\beta$ II spectrin will help develop new clinical treatment strategies. This review will advance future study of the role of membrane skeletal proteins in cancer and other diseases, particularly regarding the close intertwining of their functions and structural characteristics; provide molecular mechanisms and directions for the clinical diagnosis and treatment of diseases; and provide evidence and basic insight into potential future research areas, especially neurological diseases and cancers.

\section{Acknowledgments}

This work was supported by The National Natural Science Foundation of China (grant no. 81870331, 31701208), The Natural Science Foundation of Shandong Province (grant no. ZR2017MC067), and The Qingdao municipal science and technology bureau project (grant no. 18-2-2-65-jch, 19-6-1-2-nsh).

\section{Author Contributions}

PYY wrote the manuscript and made the figures. YYY, YT and TYZ collected and prepared papers related to the manuscript. TY, PS and ZRJ revised the manuscript. PS, FG, CW and YT guided the writing of 
the manuscript. All authors read and approved the final manuscript.

\section{Abbreviations}

Akt: Protein kinase B

BMD: Bone mineral density

CDK4: Cyclin-dependent kinase 4

CEACAM1-4L: Carcinoembryonic antigen-

related cell adhesion molecule 1

CHL1: Close homolog of L1

CSC: Cancer stem cell(s)

EpCAM: Epithelial cell adhesion molecule

EOC: Epithelial ovarian cancer

EMT: Epithelial-mesenchymal-transition

ESP: Endometrial side population

FLT3: Type III receptor tyrosine kinase

GWAS: Genome-wide association studies

GSK3: Glycogen synthase kinase $3 \alpha / \beta$

HCs: Hair cells

HCC: Hepatocellular carcinoma

IL6: Interleukin 6

LSCs: Liver stem cells

LRP6: Low density lipoprotein receptor-related

protein 6

LVAD: Left ventricular assist device

MPD: Myeloproliferative disease

MPSs: Membrane-associated periodic skeletons

MAPK: Mitogen-activated protein kinase

NFkB: Nuclear factor kappa -light-chainenhancer of activated B cells

OPSCC: Oropharyngeal squamous cell

carcinoma

PI3K: Phosphoinositide 3-kinase

PMSs: Periodic membrane skeletons

PNS: Peripheral nervous system

PDGFRB: Platelet-derived growth factor receptor $\beta$

$\mathrm{Rb}$ : Retinoblastoma protein

STAT3: Transcription 3

TGF $\beta$ : Transforming growth factor $\beta$

TLR4: Toll-like receptor 4

TICs: Tumor-initiating stem-like cells

YAP: Yes-associated protein

\section{Competing Interests}

The authors have declared that no competing interest exists.

\section{References}

1. Marchesi VT, Steers E, Jr. Selective solubilization of a protein component of the red cell membrane. Science (New York, NY). 1968;159(3811):203-4.

2. Derbala MH, Guo AS, Mohler PJ, Smith SA. The role of $\beta$ II spectrin in cardiac health and disease. Life sciences. 2018;192:278-85.

3. Winkelmann JC, Forget BG. Erythroid and nonerythroid spectrins. Blood. 1993;81(12):3173-85.

4. Machnicka B, Grochowalska R, Bogusławska DM, Sikorski AF, Lecomte MC Spectrin-based skeleton as an actor in cell signaling. Cell Mol Life Sci. 2012;69(2):191-201.
5. Levine J, Willard M. Fodrin: axonally transported polypeptides associated with the internal periphery of many cells. J Cell Biol. 1981;90(3):631-42.

6. Glenney JR, Jr., Glenney P. Fodrin is the general spectrin-like protein found in most cells whereas spectrin and the TW protein have a restricted distribution. Cell. 1983;34(2):503-12.

7. Bogusławska DM, Machnicka B, Hryniewicz-Jankowska A, Czogalla A. Spectrin and phospholipids - the current picture of their fascinating interplay. Cell Mol Biol Lett. 2014;19(1):158-79.

8. Lux SEt. Anatomy of the red cell membrane skeleton: unanswered questions. Blood. 2016;127(2):187-99.

9. Bose D, Patra M, Chakrabarti A. Effect of $\mathrm{pH}$ on stability, conformation, and chaperone activity of erythroid \& non-erythroid spectrin. Biochimica et biophysica acta Proteins and proteomics. 2017;1865(6):694-702.

10. Chen S, Li J, Zhou P, Zhi X. SPTBN1 and cancer, which links? J Cell Physiol. 2020;235(1):17-25.

11. Huang CY, Rasband MN. Axon initial segments: structure, function, and disease. Ann N Y Acad Sci. 2018;1420(1):46-61.

12. Estrada K, Styrkarsdottir U, Evangelou E, Hsu YH, Duncan EL, Ntzani EE, et al. Genome-wide meta-analysis identifies 56 bone mineral density loci and reveals 14 loci associated with risk of fracture. Nat Genet. 2012;44(5):491-501.

13. Liu Y, Qi J, Chen X, Tang M, Chu C, Zhu W, et al. Critical role of spectrin in hearing development and deafness. Sci Adv. 2019;5(4):eaav7803.

14. Tang Y, Katuri V, Dillner A, Mishra B, Deng CX, Mishra L. Disruption of transforming growth factor-beta signaling in ELF beta-spectrin-deficient mice. Science (New York, NY). 2003;299(5606):574-7.

15. Kirkpatrick F. Spectrin: current understanding of its physical, biochemical, and functional properties. Life sciences. 1976;19(1):1-17.

16. Speicher DW, Marchesi VT. Erythrocyte spectrin is comprised of many homologous triple helical segments. Nature. 1984;311(5982):177-80.

17. Smith SA, Sturm AC, Curran J, Kline CF, Little SC, Bonilla IM, et al. Dysfunction in the $\beta \mathrm{II}$ spectrin-dependent cytoskeleton underlies human arrhythmia. Circulation. 2015;131(8):695-708

18. Broderick MJ, Winder SJ. Spectrin, alpha-actinin, and dystrophin. Adv Protein Chem. 2005;70:203-46.

19. Baines AJ. Evolution of spectrin function in cytoskeletal and membrane networks. Biochem Soc Trans. 2009;37(Pt 4):796-803.

20. Liem RK. Cytoskeletal Integrators: The Spectrin Superfamily. Cold Spring Harb Perspect Biol. 2016;8(10).

21. Viel A, Branton D. Spectrin: on the path from structure to function. Curr Opin Cell Biol. 1996;8(1):49-55.

22. Castresana J, Saraste M. Does Vav bind to F-actin through a CH domain? FEBS Lett. 1995;374(2):149-51.

23. Davis L, Abdi K, Machius M, Brautigam C, Tomchick DR, Bennett V, et al. Localization and structure of the ankyrin-binding site on beta2-spectrin. J Biol Chem. 2009;284(11):6982-7.

24. Bignone PA, King MD, Pinder JC, Baines AJ. Phosphorylation of a threonine unique to the short C-terminal isoform of betalI-spectrin links regulation of alpha-beta spectrin interaction to neuritogenesis. J Biol Chem. 2007;282(2):888-96

25. Zhang P, Talluri S, Deng H, Branton D, Wagner G. Solution structure of the pleckstrin homology domain of Drosophila beta-spectrin. Structure. 1995:3(11):1185-95.

26. Wasenius VM, Saraste M, Salvén P, Erämaa M, Holm L, Lehto VP. Primary structure of the brain alpha-spectrin. J Cell Biol. 1989;108(1):79-93.

27. Travé G, Pastore A, Hyvönen M, Saraste M. The C-terminal domain of alpha-spectrin is structurally related to calmodulin. Eur J Biochem. 1995;227(1-2):35-42.

28. Wang Z, Song $Y, T u W$, He $X$, Lin J, Liu F. $\beta-2$ spectrin is involved in hepatocyte proliferation through the interaction of TGF $\beta / S m a d$ and PI3K/AKT signalling. Liver Int. 2012;32(7):1103-11.

29. Meyer C, Dzieran J, Liu Y, Schindler F, Munker S, Müller A, et al. Distinct dedifferentiation processes affect caveolin-1 expression in hepatocytes. Cell Commun Signal. 2013;11(1):6.

30. Chen Y, Meng L, Shang H, Dou Q, Lu Z, Liu L, et al. $\beta 2$ spectrin-mediated differentiation repressed the properties of liver cancer stem cells through $\beta$-catenin. Cell death \& disease. 2018;9(4):424.

31. Baek HJ, Lim SC, Kitisin K, Jogunoori W, Tang Y, Marshall MB, et al. Hepatocellular cancer arises from loss of transforming growth factor beta signaling adaptor protein embryonic liver fodrin through abnormal angiogenesis. Hepatology. 2008;48(4):1128-37.

32. Kitisin K, Ganesan N, Tang Y, Jogunoori W, Volpe EA, Kim SS, et al. Disruption of transforming growth factor-beta signaling through beta-spectrin ELF leads to hepatocellular cancer through cyclin D1 activation. Oncogene. 2007;26(50):7103-10.

33. Mitra A, Yan J, Xia X, Zhou S, Chen J, Mishra L, et al. IL6-mediated inflammatory loop reprograms normal to epithelial-mesenchymal transition $(+)$ metastatic cancer stem cells in preneoplastic liver of transforming growth factor beta-deficient $\beta 2$-spectrin(+/-) mice. Hepatology. 2017;65(4):1222-36.

34. Salzer JL, Brophy PJ, Peles E. Molecular domains of myelinated axons in the peripheral nervous system. Glia. 2008;56(14):1532-40.

35. Ogawa Y, Schafer DP, Horresh I, Bar V, Hales K, Yang Y, et al. Spectrins and ankyrinB constitute a specialized paranodal cytoskeleton. The Journal of neuroscience : the official journal of the Society for Neuroscience. 2006;26(19):5230-9. 
36. Arancibia-Carcamo IL, Attwell D. The node of Ranvier in CNS pathology. Acta Neuropathol. 2014;128(2):161-75.

37. Gollan L, Sabanay H, Poliak S, Berglund EO, Ranscht B, Peles E. Retention of a cell adhesion complex at the paranodal junction requires the cytoplasmic region of Caspr. J Cell Biol. 2002;157(7):1247-56.

38. Zhang Y, Yuen S, Peles E, Salzer JL. Accumulation of Neurofascin at Nodes of Ranvier Is Regulated by a Paranodal Switch. The Journal of neuroscience : the official journal of the Society for Neuroscience. 2020;40(30):5709-23.

39. Brivio V, Faivre-Sarrailh C, Peles E, Sherman DL, Brophy PJ. Assembly of CNS Nodes of Ranvier in Myelinated Nerves Is Promoted by the Axon Cytoskeleton. Curr Biol. 2017;27(7):1068-73.

40. Eshed-Eisenbach Y, Peles E. Axonal spectrins: all-purpose fences. J Cell Biol. 2013;203(3):381-3.

41. Feinberg K, Eshed-Eisenbach Y, Frechter S, Amor V, Salomon D, Sabanay H, et al. A glial signal consisting of gliomedin and NrCAM clusters axonal $\mathrm{Na}+$ channels during the formation of nodes of Ranvier. Neuron. 2010;65(4):490-502

42. Amor V, Zhang C, Vainshtein A, Zhang A, Zollinger DR, Eshed-Eisenbach Y, et al. The paranodal cytoskeleton clusters $\mathrm{Na}(+)$ channels at nodes of Ranvier. Elife. 2017;6.

43. D'Este E, Kamin D, Balzarotti F, Hell SW. Ultrastructural anatomy of nodes of Ranvier in the peripheral nervous system as revealed by STED microscopy. Proc Natl Acad Sci U S A. 2017;114(2):E191-e9.

44. Qu Y, Hahn I, Webb SE, Pearce SP, Prokop A. Periodic actin structures in neuronal axons are required to maintain microtubules. Mol Biol Cell. 2017;28(2):296-308

45. Galiano MR, Jha S, Ho TS, Zhang C, Ogawa Y, Chang KJ, et al. A distal axonal cytoskeleton forms an intra-axonal boundary that controls axon initial segment assembly. Cell. 2012;149(5):1125-39.

46. Lorenzo DN, Badea A, Zhou R, Mohler PJ, Zhuang X, Bennett V. $\beta I I-$ spectrin promotes mouse brain connectivity through stabilizing axonal plasma membranes and enabling axonal organelle transport. Proc Natl Acad Sci U S A. 2019;116(31):15686-95.

47. Leterrier C. A dual role for $\beta$ II-spectrin in axons. Proc Natl Acad Sci U S A. 2019;116(31):15324-6.

48. Susuki K, Raphael AR, Ogawa Y, Stankewich MC, Peles E, Talbot WS, et al. Schwann cell spectrins modulate peripheral nerve myelination. Proc Natl Acad Sci U S A. 2011:108(19):8009-14.

49. Susuki K, Zollinger DR, Chang KJ, Zhang C, Huang CY, Tsai CR, et al. Glial $\beta I I$ Spectrin Contributes to Paranode Formation and Maintenance. The Journal of neuroscience : the official journal of the Society for Neuroscience. 2018;38(27):6063-75

50. Rodriguez-Boulan E, Nelson WJ. Morphogenesis of the polarized epithelial cell phenotype. Science (New York, NY). 1989;245(4919):718-25.

51. Naydenov NG, Ivanov AI. Adducins regulate remodeling of apical junctions in human epithelial cells. Mol Biol Cell. 2010;21(20):3506-17.

52. Bazellières E, Massey-Harroche D, Barthélémy-Requin M, Richard F, Arsanto JP, Le Bivic A. Apico-basal elongation requires a drebrin-E-EB3 complex in columnar human epithelial cells. J Cell Sci. 2012;125(Pt 4):919-31.

53. He M, Abdi KM, Bennett V. Ankyrin-G palmitoylation and $\beta I I-s p e c t r i n$ binding to phosphoinositide lipids drive lateral membrane assembly. J Cell Biol. 2014;206(2):273-88.

54. Abdi KM, Bennett V. Adducin promotes micrometer-scale organization of beta2-spectrin in lateral membranes of bronchial epithelial cells. Mol Biol Cell. 2008;19(2):536-45.

55. Lechuga S, Amin PH, Wolen AR, Ivanov AI. Adducins inhibit lung cancer cell migration through mechanisms involving regulation of cell-matrix adhesion and cadherin-11 expression. Biochim Biophys Acta Mol Cell Res. 2019;1866(3):395-408.

56. Wang $\mathrm{Y}$, Zhang H, Kang Q, Liu J, Weng H, Li W, et al. Protein $4.1 \mathrm{~N}$ is required for the formation of the lateral membrane domain in human bronchial epithelial cells. Biochim Biophys Acta Biomembr. 2018;1860(5):1143-51.

57. Benz PM, Merkel CJ, Offner K, Abeßer M, Ullrich M, Fischer T, et al. Mena/VASP and aII-Spectrin complexes regulate cytoplasmic actin networks in cardiomyocytes and protect from conduction abnormalities and dilated cardiomyopathy. Cell Commun Signal. 2013;11:56

58. El Refaey MM, Mohler PJ. Ankyrins and Spectrins in Cardiovascular Biology and Disease. Front Physiol. 2017:8:852

59. Lim JA, Baek HJ, Jang MS, Choi EK, Lee YM, Lee SJ, et al. Loss of $\beta 2$-spectrin prevents cardiomyocyte differentiation and heart development. Cardiovasc Res. 2014;101(1):39-47.

60. Furness DN, Mahendrasingam S, Ohashi M, Fettiplace R, Hackney CM. The dimensions and composition of stereociliary rootlets in mammalian cochlear hair cells: comparison between high- and low-frequency cells and evidence for a connection to the lateral membrane. The Journal of neuroscience : the official journal of the Society for Neuroscience. 2008;28(25):6342-53.

61. Zhi X, Lin L, Yang S, Bhuvaneshwar K, Wang H, Gusev Y, et al. $\beta$ II-Spectrin (SPTBN1) suppresses progression of hepatocellular carcinoma and Wnt signaling by regulation of Wnt inhibitor kallistatin. Hepatology. 2015;61(2):598-612.

62. Ferrigno O, Lallemand F, Verrecchia F, L'Hoste S, Camonis J, Atfi A, et al. Yes-associated protein (YAP65) interacts with Smad7 and potentiates its inhibitory activity against TGF-beta/Smad signaling. Oncogene. 2002;21(32):4879-84.
63. Kiriyama S, Yokoyama S, Ueno M, Hayami S, Ieda J, Yamamoto N, et al. CEACAM1 long cytoplasmic domain isoform is associated with invasion and recurrence of hepatocellular carcinoma. Ann Surg Oncol. 2014;21 Suppl 4(0 4):S505-14.

64. Tian N, Leshchyns'ka I, Welch JH, Diakowski W, Yang H, Schachner M, et al. Lipid raft-dependent endocytosis of close homolog of adhesion molecule L1 (CHL1) promotes neuritogenesis. J Biol Chem. 2012;287(53):44447-63.

65. Gau DM, Lesnock JL, Hood BL, Bhargava R, Sun M, Darcy K, et al. BRCA1 deficiency in ovarian cancer is associated with alteration in expression of several key regulators of cell motility - A proteomics study. Cell Cycle. 2015;14(12):1884-92.

66. Yokota M, Kojima M, Higuchi Y, Nishizawa Y, Kobayashi A, Ito M, et al. Gene expression profile in the activation of subperitoneal fibroblasts reflects prognosis of patients with colon cancer. Int J Cancer. 2016;138(6):1422-31.

67. Ewan KB, Henshall-Powell RL, Ravani SA, Pajares MJ, Arteaga C, Warters R, et al. Transforming growth factor-beta1 mediates cellular response to DNA damage in situ. Cancer Res. 2002;62(20):5627-31.

68. Chen J, Shukla V, Farci P, Andricovich J, Jogunoori W, Kwong LN, et al. Loss of the transforming growth factor- $\beta$ effector $\beta 2$-Spectrin promotes genomic instability. Hepatology. 2017;65(2):678-93.

69. Baek HJ, Kim SS, da Silva FM, Volpe EA, Evans S, Mishra B, et al. Inactivation of TGF-beta signaling in lung cancer results in increased CDK4 activity that can be rescued by ELF. Biochem Biophys Res Commun. 2006;346(4):1150-7.

70. Huang TC, Renuse S, Pinto S, Kumar P, Yang Y, Chaerkady R, et al. Identification of miR-145 targets through an integrated omics analysis. Mol Biosyst. 2015;11(1):197-207

71. Mendelson J, Song S, Li Y, Maru DM, Mishra B, Davila M, et al. Dysfunctional transforming growth factor- $\beta$ signaling with constitutively active Notch signaling in Barrett's esophageal adenocarcinoma. Cancer. 2011;117(16):3691-702.

72. Thomas MB, Zhu AX. Hepatocellular carcinoma: the need for progress. J Clin Oncol. 2005;23(13):2892-9.

73. Jiang X, Gillen S, Esposito I, Giese NA, Michalski CW, Friess H, et al. Reduced expression of the membrane skeleton protein beta1-spectrin (SPTBN1) is associated with worsened prognosis in pancreatic cancer. Histol Histopathol. 2010;25(12):1497-506.

74. Lin L, Yao Z, Bhuvaneshwar K, Gusev Y, Kallakury B, Yang S, et al. Transcriptional regulation of STAT3 by SPTBN1 and SMAD3 in HCC through cAMP-response element-binding proteins ATF3 and CREB2. Carcinogenesis. 2014;35(11):2393-403.

75. Yamashita T, Budhu A, Forgues M, Wang XW. Activation of hepatic stem cell marker EpCAM by Wnt-beta-catenin signaling in hepatocellular carcinoma. Cancer Res. 2007;67(22):10831-9.

76. Wang W, Smits R, Hao H, He C. Wnt/ $\beta$-Catenin Signaling in Liver Cancers. Cancers (Basel). 2019;11(7).

77. Tian Y, Mok MT, Yang P, Cheng AS. Epigenetic Activation of Wnt/ $\beta$-Catenin Signaling in NAFLD-Associated Hepatocarcinogenesis. Cancers (Basel). 2016;8(8).

78. Dimri M, Satyanarayana A. Molecular Signaling Pathways and Therapeutic Targets in Hepatocellular Carcinoma. Cancers (Basel). 2020;12(2).

79. Tsukamoto H, Mishra L, Machida K. Alcohol, TLR4-TGF- $\beta$ antagonism, and liver cancer. Hepatol Int. 2014;8 Suppl 2(Suppl 2):408-12.

80. Chen CL, Tsukamoto H, Liu JC, Kashiwabara C, Feldman D, Sher L, et al. Reciprocal regulation by TLR4 and TGF- $\beta$ in tumor-initiating stem-like cells. J Clin Invest. 2013;123(7):2832-49.

81. Shen C, Yu Y, Li H, Yan G, Liu M, Shen H, et al. Global profiling of proteolytically modified proteins in human metastatic hepatocellular carcinoma cell lines reveals CAPN2 centered network. Proteomics. 2012;12(12):1917-27.

82. Mantini G, Vallés AM, Le Large TYS, Capula M, Funel N, Pham TV, et al. Co-expression analysis of pancreatic cancer proteome reveals biology and prognostic biomarkers. Cellular oncology (Dordrecht). 2020.

83. Li M, Yang Y, Wang Z, Zong T, Fu X, Aung LHH, et al. Piwi-interacting RNAs (piRNAs) as potential biomarkers and therapeutic targets for cardiovascular diseases. Angiogenesis. 2020.

84. Bai B, Yang Y, Wang Q, Li M, Tian C, Liu Y, et al. NLRP3 inflammasome in endothelial dysfunction. Cell death \& disease. 2020;11(9):776.

85. He X, Lian Z, Yang Y, Wang Z, Fu X, Liu Y, et al. Long Non-coding RNA PEBP1P2 Suppresses Proliferative VSMCs Phenotypic Switching and Proliferation in Atherosclerosis. Molecular therapy Nucleic acids. 2020;22:84-98.

86. Cheng M, Yang Y, Xin H, Li M, Zong T, He X, et al. Non-coding RNAs in aortic dissection: From biomarkers to therapeutic targets. Journal of cellular and molecular medicine. 2020.

87. Wang $\mathrm{Q}$, Yang $\mathrm{Y}, \mathrm{Fu} \mathrm{X}$, Wang $\mathrm{Z}$, Liu $\mathrm{Y}$, Li M, et al. Long noncoding RNA XXYLT1-AS2 regulates proliferation and adhesion by targeting the RNA binding protein FUS in HUVEC. Atherosclerosis. 2020;298:58-69.

88. Liu Y, Yang Y, Wang Z, Fu X, Chu XM, Li Y, et al. Insights into the regulatory role of circRNA in angiogenesis and clinical implications. Atherosclerosis. 2020;298:14-26

89. Liu S, Yang Y, Jiang S, Xu H, Tang N, Lobo A, et al. MiR-378a-5p Regulates Proliferation and Migration in Vascular Smooth Muscle Cell by Targeting CDK1. Frontiers in genetics. 2019;10:22. 
90. Tang N, Jiang S, Yang Y, Liu S, Ponnusamy M, Xin H, et al. Noncoding RNAs as therapeutic targets in atherosclerosis with diabetes mellitus. Cardiovascular therapeutics. 2018;36(4):e12436.

91. Liu S, Yang Y, Jiang S, Tang N, Tian J, Ponnusamy M, et al. Understanding the role of non-coding RNA (ncRNA) in stent restenosis. Atherosclerosis. 2018;272:153-61.

92. Yang $\mathrm{Y}, \mathrm{Yu} \mathrm{T}$, Jiang $\mathrm{S}$, Zhang $\mathrm{Y}, \mathrm{Li} \mathrm{M}$, Tang $\mathrm{N}$, et al. miRNAs as potential therapeutic targets and diagnostic biomarkers for cardiovascular disease with a particular focus on WO2010091204. Expert opinion on therapeutic patents. 2017;27(9):1021-9.

93. Yao ZX, Jogunoori W, Choufani S, Rashid A, Blake T, Yao W, et al. Epigenetic silencing of beta-spectrin, a TGF-beta signaling/scaffolding protein in a human cancer stem cell disorder: Beckwith-Wiedemann syndrome. J Biol Chem. 2010;285(46):36112-20.

94. Yu T, Wang Z, Jie W, Fu X, Li B, Xu H, et al. The kinase inhibitor BX795 suppresses the inflammatory response via multiple kinases. Biochemical pharmacology. 2020;174:113797.

95. Harpaz N, Polydorides AD. Colorectal dysplasia in chronic inflammatory bowel disease: pathology, clinical implications, and pathogenesis. Archives of pathology \& laboratory medicine. 2010;134(6):876-95.

96. Ying J, Lin C, Wu J, Guo L, Qiu T, Ling Y, et al. Anaplastic Lymphoma Kinase Rearrangement in Digestive Tract Cancer: Implication for Targeted Therapy in Chinese Population. PLoS One. 2015;10(12):e0144731.

97. Lasota J, Chłopek M, Wasąg B, Kowalik A, Christiansen J, Lamoureux J, et al. Colorectal Adenocarcinomas Harboring ALK Fusion Genes: A Clinicopathologic and Molecular Genetic Study of 12 Cases and Review of the Literature. The American journal of surgical pathology. 2020;44(9):1224-34.

98. Artavanis-Tsakonas S, Rand MD, Lake RJ. Notch signaling: cell fate control and signal integration in development. Science (New York, NY). 1999;284(5415):770-6

99. Katuri V, Tang Y, Marshall B, Rashid A, Jogunoori W, Volpe EA, et al. Inactivation of ELF/TGF-beta signaling in human gastrointestinal cancer. Oncogene. 2005;24(54):8012-24.

100. Katuri V, Tang Y, Li C, Jogunoori W, Deng CX, Rashid A, et al. Critical interactions between TGF-beta signaling/ELF, and E-cadherin/beta-catenin mediated tumor suppression. Oncogene. 2006;25(13):1871-86.

101. Kim SS, Shetty K, Katuri V, Kitisin K, Baek HJ, Tang Y, et al. TGF-beta signaling pathway inactivation and cell cycle deregulation in the development of gastric cancer: role of the beta-spectrin, ELF. Biochem Biophys Res Commun. 2006;344(4):1216-23.

102. Gu FF, Zhang Y, Liu YY, Hong XH, Liang JY, Tong $F$, et al. Lung adenocarcinoma harboring concomitant SPTBN1-ALK fusion, c-Met overexpression, and HER-2 amplification with inherent resistance to crizotinib, chemotherapy, and radiotherapy. J Hematol Oncol. 2016;9(1):66

103. Grønhøj C, Jensen DH, Agander T, Kiss K, Høgdall E, Specht L, et al. Deep sequencing of human papillomavirus positive loco-regionally advanced oropharyngeal squamous cell carcinomas reveals novel mutational signature. BMC Cancer. 2018;18(1):640.

104. Yang SF, Bier-Laning CM, Adams W, Zilliox MJ. Candidate Biomarkers for HPV-Negative Head and Neck Cancer Identified via Gene Expression Barcode Analysis. Otolaryngol Head Neck Surg. 2016;155(3):416-22.

105. Chen M, Zeng J, Chen S, Li J, Wu H, Dong X, et al. SPTBN1 suppresses the progression of epithelial ovarian cancer via SOCS3-mediated blockade of the JAK/STAT3 signaling pathway. Aging. 2020;12(11):10896-911.

106. Maeda $O$, Shibata $K$, Hosono $S$, Fujiwara $S$, Kajiyama $H$, Ino $K$, et al. Spectrin aII and $\beta I I$ tetramers contribute to platinum anticancer drug resistance in ovarian serous adenocarcinoma. Int J Cancer. 2012;130(1):113-21.

107. Li DD, Deng L, Hu SY, Zhang FL, Li DQ. SH3BGRL2 exerts a dual function in breast cancer growth and metastasis and is regulated by TGF- $\beta 1$. Am J Cancer Res. 2020;10(4):1238-54.

108. Gorman EB, Chen L, Albanese J, Ratech H. Patterns of spectrin expression in B-cell lymphomas: loss of spectrin isoforms is associated with nodule-forming and germinal center-related lymphomas. Mod Pathol. 2007;20(12):1245-52.

109. Xu Y, Han W, Xu WH, Wang Y, Yang XL, Nie HL, et al. Identification of differentially expressed genes and functional annotations associated with metastases of the uveal melanoma. J Cell Biochem. 2019;120(11):19202-14.

110. Baines AJ, Pinder JC. The spectrin-associated cytoskeleton in mammalian heart. Front Biosci. 2005;10:3020-33.

111. Mohler PJ, Rivolta I, Napolitano C, LeMaillet G, Lambert S, Priori SG, et al. Nav1.5 E1053K mutation causing Brugada syndrome blocks binding to ankyrin-G and expression of Nav1.5 on the surface of cardiomyocytes. Proc Natl Acad Sci U S A. 2004:101(50):17533-8.

112. Fu Y, Xiao S, Hong T, Shaw RM. Cytoskeleton regulation of ion channels. Circulation. 2015;131(8):689-91.

113. Barton PJ, Birks EJ, Felkin LE, Cullen ME, Koban MU, Yacoub MH. Increased expression of extracellular matrix regulators TIMP1 and MMP1 in deteriorating heart failure. J Heart Lung Transplant. 2003;22(7):738-44.

114. Smith SA, Hughes LD, Kline CF, Kempton AN, Dorn LE, Curran J, et al. Dysfunction of the $\beta 2$-spectrin-based pathway in human heart failure. Am J Physiol Heart Circ Physiol. 2016;310(11):H1583-91.

115. Kempton A, Cefalu M, Justice C, Baich T, Derbala M, Canan B, et al. Altered regulation of cardiac ankyrin repeat protein in heart failure. Heliyon. 2018;4(1):e00514

116. Grand FH, Iqbal S, Zhang L, Russell NH, Chase A, Cross NC. A constitutively active SPTBN1-FLT3 fusion in atypical chronic myeloid leukemia is sensitive to tyrosine kinase inhibitors and immunotherapy. Exp Hematol. 2007;35(11):1723-7.

117. Gallagher G, Horsman DE, Tsang P, Forrest DL. Fusion of PRKG2 and SPTBN1 to the platelet-derived growth factor receptor beta gene (PDGFRB) in imatinib-responsive atypical myeloproliferative disorders. Cancer Genet Cytogenet. 2008;181(1):46-51.

118. Rivadeneira F, Styrkársdottir U, Estrada K, Halldórsson BV, Hsu YH, Richards $\mathrm{JB}$, et al. Twenty bone-mineral-density loci identified by large-scale meta-analysis of genome-wide association studies. Nat Genet. 2009;41(11):1199-206.

119. Styrkarsdottir U, Halldorsson BV, Gretarsdottir S, Gudbjartsson DF, Walters GB, Ingvarsson T, et al. Multiple genetic loci for bone mineral density and fractures. N Engl J Med. 2008;358(22):2355-65.

120. Styrkarsdottir U, Halldorsson BV, Gretarsdottir S, Gudbjartsson DF, Walters $\mathrm{GB}$, Ingvarsson $\mathrm{T}$, et al. New sequence variants associated with bone mineral density. Nat Genet. 2009;41(1):15-7.

121. Ma M, Huang DG, Liang X, Zhang $L$, Cheng $S$, Cheng $B$, et al. Integrating transcriptome-wide association study and mRNA expression profiling identifies novel genes associated with bone mineral density. Osteoporos Int. 2019;30(7):1521-8.

122. Park S, Daily JW, Song MY, Kwon HK. Gene-gene and gene-lifestyle interactions of AKAP11, KCNMA1, PUM1, SPTBN1, and EPDR1 on osteoporosis risk in middle-aged adults. Nutrition (Burbank, Los Angeles County, Calif). 2020;79-80:110859.

123. Hu Y, Tan LJ, Chen XD, Liu Z, Min SS, Zeng Q, et al. Identification of Novel Potentially Pleiotropic Variants Associated With Osteoporosis and Obesity Using the cFDR Method. J Clin Endocrinol Metab. 2018;103(1):125-38.

124. Pepe J, Bonnet N, Herrmann FR, Biver E, Rizzoli R, Chevalley T, et al. Interaction between LRP5 and periostin gene polymorphisms on serum periostin levels and cortical bone microstructure. Osteoporos Int. 2018:29(2):339-46.

125. Wang C, Zhang Z, Zhang H, He JW, Gu JM, Hu WW, et al. Susceptibility genes for osteoporotic fracture in postmenopausal Chinese women. J Bone Miner Res. 2012;27(12):2582-91.

126. Liu JM, Zhang MJ, Zhao L, Cui B, Li ZB, Zhao HY, et al. Analysis of recently identified osteoporosis susceptibility genes in Han Chinese women. J Clin Endocrinol Metab. 2010;95(9):E112-20.

127. Calabrese GM, Mesner LD, Stains JP, Tommasini SM, Horowitz MC, Rosen CJ, et al. Integrating GWAS and Co-expression Network Data Identifies Bone Mineral Density Genes SPTBN1 and MARK3 and an Osteoblast Functional Module. Cell Syst. 2017;4(1):46-59.e4.

128. Hsu YH, Kiel DP. Clinical review: Genome-wide association studies of skeletal phenotypes: what we have learned and where we are headed. J Clin Endocrinol Metab. 2012;97(10):E1958-77.

129. Xu K, Zhong G, Zhuang X. Actin, spectrin, and associated proteins form a periodic cytoskeletal structure in axons. Science (New York, NY). 2013;339(6118):452-6.

130. Zhong G, He J, Zhou R, Lorenzo D, Babcock HP, Bennett $V$, et al. Developmental mechanism of the periodic membrane skeleton in axons. Elife. 2014;3.

131. Wang G, Simon DJ, Wu Z, Belsky DM, Heller E, O'Rourke MK, et al. Structural plasticity of actin-spectrin membrane skeleton and functional role of actin and spectrin in axon degeneration. Elife. 2019;8.

132. Leverenz JB, Umar I, Wang Q, Montine TJ, McMillan PJ, Tsuang DW, et al. Proteomic identification of novel proteins in cortical lewy bodies. Brain Pathol. 2007;17(2):139-45.

133. Lee HJ, Lee K, Im H. a-Synuclein modulates neurite outgrowth by interacting with SPTBN1. Biochem Biophys Res Commun. 2012;424(3):497-502.

134. Pielage J, Fetter RD, Davis GW. Presynaptic spectrin is essential for synapse stabilization. Curr Biol. 2005;15(10):918-28.

135. Sikorski AF, Terlecki G, Zagon IS, Goodman SR. Synapsin I-mediated interaction of brain spectrin with synaptic vesicles. J Cell Biol. 1991;114(2):313-8.

136. Sikorski AF, Sangerman J, Goodman SR, Critz SD. Spectrin (betaSpIIsigma1) is an essential component of synaptic transmission. Brain Res. 2000;852(1):161-6.

137. Peuralinna T, Myllykangas L, Oinas M, Nalls MA, Keage HA, Isoviita VM, et al. Genome-wide association study of neocortical Lewy-related pathology. Ann Clin Transl Neurol. 2015;2(9):920-31.

138. Sainio M, Zhao F, Heiska L, Turunen O, den Bakker M, Zwarthoff E, et al. Neurofibromatosis 2 tumor suppressor protein colocalizes with ezrin and CD44 and associates with actin-containing cytoskeleton. J Cell Sci. 1997;110 ( Pt 18):2249-60.

139. Scoles DR, Huynh DP, Morcos PA, Coulsell ER, Robinson NG, Tamanoi F, et al. Neurofibromatosis 2 tumour suppressor schwannomin interacts with betaII-spectrin. Nat Genet. 1998;18(4):354-9.

140. Swaminathan S, Dai L, Lane HC, Imamichi T. Evaluating the potential of IL-27 as a novel therapeutic agent in HIV-1 infection. Cytokine Growth Factor Rev. 2013;24(6):571-7.

141. Huang L, Chen $Y$, Lin $Y$, Tam POS, Cheng $Y$, Shi $Y$, et al. Genome-wide analysis identified 17 new loci influencing intraocular pressure in Chinese population. Science China Life sciences. 2019;62(2):153-64.

142. Bennett V, Baines AJ. Spectrin and ankyrin-based pathways: metazoan inventions for integrating cells into tissues. Physiological reviews. 2001;81(3):1353-92 
143. Sarfarazi M, Akarsu AN, Hossain A, Turacli ME, Aktan SG, Barsoum-Homsy $\mathrm{M}$, et al. Assignment of a locus (GLC3A) for primary congenital glaucoma (Buphthalmos) to 2p21 and evidence for genetic heterogeneity. Genomics. 1995;30(2):171-7.

144. Tang Y, Kitisin K, Jogunoori W, Li C, Deng CX, Mueller SC, et al. Progenitor/stem cells give rise to liver cancer due to aberrant TGF-beta and IL-6 signaling. Proc Natl Acad Sci U S A. 2008;105(7):2445-50.

145. Pettenati MJ, Haines JL, Higgins RR, Wappner RS, Palmer CG, Weaver DD. Wiedemann-Beckwith syndrome: presentation of clinical and cytogenetic data on 22 new cases and review of the literature. Hum Genet. 1986;74(2):143-54

146. Chen J, Yao ZX, Chen JS, Gi YJ, Muñoz NM, Kundra S, et al. TGF- $\beta / \beta 2$-spectrin/CTCF-regulated tumor suppression in human stem cell disorder Beckwith-Wiedemann syndrome. J Clin Invest. 2016;126(2):527-42.

147. Kriseman M, Monsivais D, Agno J, Masand RP, Creighton CJ, Matzuk MM. Uterine double-conditional inactivation of Smad2 and Smad3 in mice causes endometrial dysregulation, infertility, and uterine cancer. Proc Natl Acad Sci U S A. 2019;116(9):3873-82.

148. Tang Y, Katuri V, Srinivasan R, Fogt F, Redman R, Anand G, et al. Transforming growth factor-beta suppresses nonmetastatic colon cancer through Smad4 and adaptor protein ELF at an early stage of tumorigenesis. Cancer Res. 2005;65(10):4228-37.

149. Chen YC, Guo YF, He H, Lin X, Wang XF, Zhou R, et al. Integrative Analysis of Genomics and Transcriptome Data to Identify Potential Functional Genes of BMDs in Females. J Bone Miner Res. 2016;31(5):1041-9. 